\title{
Comparing parameterized versus measured microphysical properties of tropical convective cloud bases during the ACRIDICON-CHUVA campaign
}

\author{
Ramon Campos Braga ${ }^{1}$, Daniel Rosenfeld ${ }^{2}$, Ralf Weigel ${ }^{3}$, Tina Jurkat ${ }^{4}$, Meinrat O. Andreae ${ }^{5,9}$, Manfred Wendisch ${ }^{6}$, \\ Mira L. Pöhlker ${ }^{5}$, Thomas Klimach ${ }^{5}$, Ulrich Pöschll ${ }^{5}$, Christopher Pöhlker ${ }^{5}$, Christiane Voigt ${ }^{3,4}$, Christoph Mahnke ${ }^{3}$, \\ Stephan Borrmann ${ }^{3}$, Rachel I. Albrecht ${ }^{7}$, Sergej Molleker $^{8}$, Daniel A. Vila $^{1}$, Luiz A. T. Machado ${ }^{1}$, and Paulo Artaxo ${ }^{10}$ \\ ${ }^{1}$ Centro de Previsão de Tempo e Estudos Climáticos, Instituto Nacional de Pesquisas Espaciais, Cachoeira Paulista, Brasil \\ ${ }^{2}$ Institute of Earth Sciences, The Hebrew University of Jerusalem, Jerusalem, Israel \\ ${ }^{3}$ Institut für Physik der Atmosphäre, Johannes Gutenberg-Universität, Mainz, Germany \\ ${ }^{4}$ Institut für Physik der Atmosphäre, Deutsches Zentrum für Luft- und Raumfahrt (DLR), Oberpfaffenhofen, Germany \\ ${ }^{5}$ Multiphase Chemistry and Biogeochemistry Departments, Max Planck Institute for Chemistry, 55020 Mainz, Germany \\ ${ }^{6}$ Leipziger Institut für Meteorologie (LIM), Universität Leipzig, Stephanstr. 3, 04103 Leipzig, Germany \\ ${ }^{7}$ Instituto de Astronomia, Geofísica e Ciências Atmosféricas, Universidade de São Paulo, São Paulo, Brazil \\ ${ }^{8}$ Max Planck Institute for Chemistry (MPI), Particle Chemistry Department, Mainz, Germany \\ ${ }^{9}$ Scripps Institution of Oceanography, University of California San Diego, La Jolla, California 92037, USA \\ ${ }^{10}$ Instituto de Física (IF), Universidade de São Paulo (USP), São Paulo, Brazil
}

Correspondence to: Ramon Campos Braga (ramonbraga87@gmail.com)

Received: 29 September 2016 - Discussion started: 16 December 2016

Revised: 13 May 2017 - Accepted: 15 May 2017 - Published: 20 June 2017

\begin{abstract}
The objective of this study is to validate parameterizations that were recently developed for satellite retrievals of cloud condensation nuclei supersaturation spectra, $N_{\mathrm{CCN}}(S)$, at cloud base alongside more traditional parameterizations connecting $N_{\mathrm{CCN}}(S)$ with cloud base updrafts and drop concentrations. This was based on the HALO aircraft measurements during the ACRIDICON-CHUVA campaign over the Amazon region, which took place in September 2014. The properties of convective clouds were measured with a cloud combination probe (CCP), a cloud and aerosol spectrometer (CAS-DPOL), and a CCN counter onboard the HALO aircraft. An intercomparison of the cloud drop size distributions (DSDs) and the cloud water content (CWC) derived from the different instruments generally shows good agreement within the instrumental uncertainties. To this end, the directly measured cloud drop concentrations $\left(N_{\mathrm{d}}\right)$ near cloud base were compared with inferred values based on the measured cloud base updraft velocity $\left(W_{\mathrm{b}}\right)$ and $N_{\mathrm{CCN}}(S)$ spectra. The measurements of $N_{\mathrm{d}}$ at cloud base were also compared with drop concentrations $\left(N_{\mathrm{a}}\right)$ derived on the ba-
\end{abstract}

sis of an adiabatic assumption and obtained from the vertical evolution of cloud drop effective radius $\left(r_{\mathrm{e}}\right)$ above cloud base. The measurements of $N_{\mathrm{CCN}}(S)$ and $W_{\mathrm{b}}$ reproduced the observed $N_{\mathrm{d}}$ within the measurements uncertainties when the old (1959) Twomey's parameterization was used. The agreement between the measured and calculated $N_{\mathrm{d}}$ was only within a factor of 2 with attempts to use cloud base $S$, as obtained from the measured $W_{\mathrm{b}}, N_{\mathrm{d}}$, and $N_{\mathrm{CCN}}(S)$. This underscores the yet unresolved challenge of aircraft measurements of $S$ in clouds. Importantly, the vertical evolution of $r_{\mathrm{e}}$ with height reproduced the observation-based nearly adiabatic cloud base drop concentrations, $N_{\mathrm{a}}$. The combination of these results provides aircraft observational support for the various components of the satellite-retrieved methodology that was recently developed to retrieve $N_{\mathrm{CCN}}(S)$ under the base of convective clouds. This parameterization can now be applied with the proper qualifications to cloud simulations and satellite retrievals. 


\section{Introduction}

An understanding of cloud formation and its influence on the global hydrological cycle and radiation budget is fundamental for improving weather and climate forecasting models (Ten Hoeve et al., 2011; Jiang and Feingold, 2006; Kohler, 1999; Rosenfeld et al., 2008; Stephens, 1984). The goal of cloud microphysical models is to reproduce atmospheric processes based on physical relationships developed from field experiments and remote sensing observations in different parts of the globe (Silva Dias et al., 2002; Machado et al., 2014; Fan et al., 2014; Rosenfeld et al., 2014b). Data from aircraft probes provide opportunities to validate and improve cloud models and satellite retrievals of cloud microphysical properties.

An assessment of the validity of the cloud probe data is essential before the results can be implemented into cloud models. According to previous studies, the number concentration of cloud droplets $\left(N_{\mathrm{d}}\right)$ expected at cloud base mainly depends on the atmospheric conditions just below cloud base, i.e., updraft wind speed and the supersaturation $(S)$ activation spectra of cloud condensation nuclei $\left[N_{\mathrm{CCN}}(S)\right]$ (Pinsky et al., 2012; Reutter et al., 2009; Twomey, 1959). From cloud condensation nuclei counter (CCNC) measurements across a range of supersaturations $(S)$, the parameters $N_{0}$ and $k$ are estimated from Twomey's formula (Twomey, 1959):

$N_{\mathrm{CCN}}=N_{0} \cdot S^{k}$,

where $N_{0}$ is the cloud condensation nuclei (CCN) concentration at $S=1 \%$ in $\mathrm{cm}^{-3}$, and $k$ is the slope parameter (Twomey, 1959). Equation (1) is an analytical representation of the observational data within the measured range of $S$, which in our case represents the observed $\mathrm{CCN}$ spectrum from 0.2 to $0.55 \%$. Note, however, that Eq. (1) does not allow for a reliable extrapolation of $N_{\mathrm{CCN}}(S)$ beyond this range (Pöhlker et al., 2016).

The parameters $N_{0}$ and $k$ are estimated from data measured below cloud base along with updraft wind speed measurements at cloud base $\left(W_{\mathrm{b}}\right)$. The values of $W_{\mathrm{b}}, N_{0}$, and $k$ are used to calculate the theoretical cloud droplet concentration from Eq. (2) (Twomey, 1959):

$N_{\mathrm{dT}}=0.88 \cdot N_{0}^{\frac{2}{k+2}} \cdot\left(0.07 \cdot W_{\mathrm{b}}^{1.5}\right)^{\frac{k}{k+2}}$,

where $N_{\mathrm{dT}}$ values are the estimated cloud base drop concentrations in $\mathrm{cm}^{-3}$. Here we compare the measured $N_{\mathrm{d}}$ to $N_{\mathrm{dT}}$ by substituting in Eq. (2) the measured $N_{\mathrm{CCN}}(S)$ in the form of $N_{0}$ and $k$, along with the measured $W_{\mathrm{b}}$.

Equations (1) and (2) are a rather simplistic parameterization. More advanced methods using the hygroscopicity parameter $\kappa$ are more accurate in representing the $\mathrm{CCN}$ spectrum (Pöhlker et al., 2016). However, in this study, using Twomey's parameterization is advantageous because the $\mathrm{CCN}$ measurements were performed within the range of $0.2-$ $0.55 \%$, in which the estimation of the $N_{0}$ and $k$ parameters using Eq. (1) does not incur significant errors in comparison with more advanced methods (Pöhlker et al., 2016). Furthermore, Twomey's parameterization also allows for the calculation of the effects of updraft wind speed on $N_{\mathrm{dT}}$ as a function of $N_{0}$ and $k$.

Another approach to estimating the number concentration of $\mathrm{CCN}$ that are expected to nucleate as droplets at cloud base is through the use of the $\kappa$-Köhler model (Petters and Kreidenweis, 2007). Based on a given dry aerosol particle size distribution (ASD), the $\kappa$-Köhler model with prescribed $W_{\mathrm{b}}$ simulates the expansion and cooling of air, the resulting changes in relative humidity, the related hygroscopic growth of aerosol particles, and the further condensational growth of cloud droplets. The input to this approach depends strongly on the measured ASD and $\kappa$ (Reutter et al., 2009).

Measurements of ASD with a passive cavity aerosol spectrometer probe (PCASP) and ultra-high-sensitivity aerosol spectrometer (UHSAS) probes were available during the campaign combining ACRIDICON (Aerosol, Cloud, Precipitation, and Radiation Interactions and Dynamics of Convective Cloud Systems) and CHUVA (Cloud processes of the main precipitation systems in Brazil: A contribUtion to cloud resolVing modeling and to the GlobAl Precipitation Measurements; Wendisch et al., 2016). However, calculating $\kappa$ from the combined CCN, PCASP, and UHSAS measurements below cloud resulted in unreasonably low $\kappa$ values (not shown), which could only be explained by hygroscopic swelling of the aerosols at ambient humidity by a large factor of up to more than 2 . This implies that the particles were not completely dried in the intake of the probe, and thus prevents a quantitative assessment of $\kappa$ based on the PCASP and $N_{\mathrm{CCN}}(S)$. A possible reason for this behavior in measurements over the Amazon is that the effective hygroscopicity parameters describing water uptake at subsaturated conditions can be substantially lower than at supersaturated conditions (Mikhailov et al., 2013). The analysis of this effect on the ASD measurements from PCASP and UHSAS below cloud base requires considerable efforts, which are beyond the scope of this paper. Also, in the case of our flight missions, a major obstacle to the use of the $\kappa$-Köhler approach is the fact that measuring the $N_{\mathrm{CCN}}(S)$ spectrum requires a much longer time than the aerosol spectrum with PCASP and/or UHSAS; thus the two measurements do not represent the same aerosol sample. This was evident from the variability in the CCN concentrations measured at fixed $S$ with one CCNC column while measuring the $N_{\mathrm{CCN}}(S)$ spectrum with the other column during the flights. The lack of these important analyses prevents the use of $\kappa$-Köhler model estimates for comparison with $N_{\mathrm{d}}$ measurements from cloud probes in the present study.

An estimation of the cloud base droplet concentrations is also possible via the calculation of the maximum supersaturation $\left(S_{\max }\right)$ at cloud base, relying on the measured $N_{\mathrm{d}}$ and $W_{\mathrm{b}}$ according to Eq. (3) (Pinsky et al., 2012): 
$S_{\max }=C \cdot W_{\mathrm{b}}^{\frac{3}{4}} \cdot N_{\mathrm{d}}^{-\frac{1}{2}}$,

where $C$ is a coefficient determined by cloud base temperature and pressure. Since the combination of $N_{\mathrm{CCN}}(S)$ and $W_{\mathrm{b}}$ determines $N_{\mathrm{d}}$ and $S_{\max }$, it is possible to compare the measured and theoretical relationships. Additionally, the estimation of adiabatic cloud droplet concentrations $\left(N_{\mathrm{a}}\right)$ from measurements of the vertical profile of cloud drop effective radius $\left(r_{\mathrm{e}}\right)$ is another alternative to evaluate the number of droplets nucleated at cloud base (Freud et al., 2011). The definition of $r_{\mathrm{e}}$ is

$r_{\mathrm{e}}=\frac{\int N(r) \cdot r^{3} \mathrm{~d} r}{\int N(r) \cdot r^{2} \mathrm{~d} r}$,

where $N$ and $r$ are the droplet concentrations and radii, respectively.

Rosenfeld et al. (2014a) have shown that the effective number concentration of droplets at cloud base $\left(N_{\mathrm{d}}^{*}\right)$ can be expressed by a single number, which depends on the effective updraft speed at cloud base $\left(W_{\mathrm{b}}^{*}\right)$. To evaluate whether the measured $N_{\mathrm{d}}^{*}$ represents the theoretically expected $N_{\mathrm{d}}^{*}$ based on the independent measurements of $N_{\mathrm{CCN}}(S)$ and $W_{\mathrm{b}}$, it is necessary to find the range of measured $W_{\mathrm{b}}^{*}$ and $N_{\mathrm{d}}^{*}$ that best fulfills the closure between the measured and indirectly calculated values. Cloud models represent the number of droplets at cloud base with a single number (Pinsky et al., 2012). Therefore, from a set of $N_{\mathrm{d}}$ measurements at cloud base, an "effective" number of droplets, $N_{\mathrm{d}}^{*}$, can be derived that represents the measurements for a set of clouds formed in the same thermodynamic conditions.

The droplet size distribution (DSD) spectrum from clouds, i.e., the DSD variability, depends on the stage of cloud development. After nucleation, the cloud droplets in rising cloud parcels grow with height mainly by condensation. Raindrops start forming when $r_{\mathrm{e}}$ reaches 13-14 $\mu \mathrm{m}$ and coalescence becomes efficient (Freud and Rosenfeld, 2012; Rosenfeld and Gutman, 1994). Accurate documentation of the vertical evolution of cloud and rain DSDs is essential for analyzing these types of microphysical processes within clouds. Assessing the quality of DSD measurements taken by the aircraft probes is thus a necessary task. This assessment can be achieved via comparisons between the cloud water content (CWC) calculated from cloud probe DSDs and the direct measurements of CWC with a hot-wire device $\left(\mathrm{CWC}_{\mathrm{h}}\right)$ for cloud penetrations at different heights (Freud et al., 2008; Rosenfeld et al., 2006). This is done in Sect. 3, and the dependence of the hot-wire measurement efficiency on drop size is taken into account.

Three cloud probes measured the DSDs onboard the HALO aircraft during the ACRIDICON-CHUVA campaign (Wendisch et al., 2016). In addition, CWC was measured by a King hot-wire probe (King et al., 1978) installed in the cloud and aerosol spectrometer (CAS-DPOL) probe.

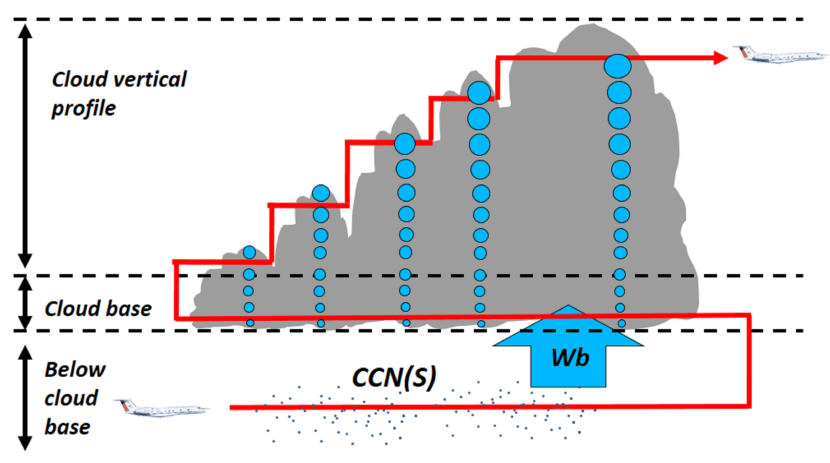

Figure 1. Flight patterns below and in convective clouds during the ACRIDICON-CHUVA campaign.

Figure 1 illustrates the HALO flight patterns in convective cloud clusters performed in three steps.

a. Flying below cloud base for measuring $N_{\mathrm{CCN}}(S)$.

b. Flying through cloud base for measuring $W_{\mathrm{b}}$ and DSD.

c. Conducting vertical profiles in growing convective towers close to their tops to avoid precipitation that may fall from above. The cloud penetrations during this phase are made in vertical steps of several hundred meters when possible from cloud base to the anvils.

The availability of these measurements collected by the same aircraft provides a unique opportunity to compare the data with theoretical predictions and to test the sensitivity of the results to the differences between the measurements taken by the cloud probes.

This study is novel in several aspects.

a. It validates the methodology of retrieving the adiabatic cloud drop concentrations $N_{\mathrm{a}}$ (Freud et al., 2011) from the vertical evolution of $r_{\mathrm{e}}$ while assuming that $r_{\mathrm{e}}$ is nearly adiabatic. This is important because it supports the validity of retrieving $N_{\mathrm{a}}$ from the satellite-retrieved vertical profile of $r_{\mathrm{e}}$ (Rosenfeld et al., 2014a, 2016).

b. It compares the aircraft-measured $N_{\mathrm{d}}$ with its parameterization that is based on $N_{\mathrm{CCN}}(S)$ along with the spectrum of updrafts at cloud base weighted by the updraft speed itself, $W_{\mathrm{b}}^{*}$. This makes it compatible with the recently developed methodology of retrieving $\mathrm{CCN}$ from satellites by means of retrieving $N_{\mathrm{d}}$ and $W_{\mathrm{b}}^{*}$ (Rosenfeld et al., 2016).

c. It observationally examines the old Twomey (1959) parameterization of the $N_{\mathrm{d}}$ dependence on $W_{\mathrm{b}}$ (Eq. 2) vs. the recent Pinsky et al. (2012) analytical expression for the same relationship (Eq. 3).

These different methodologies are presented in the next sections. Section 2 discusses the instrumentation and database 


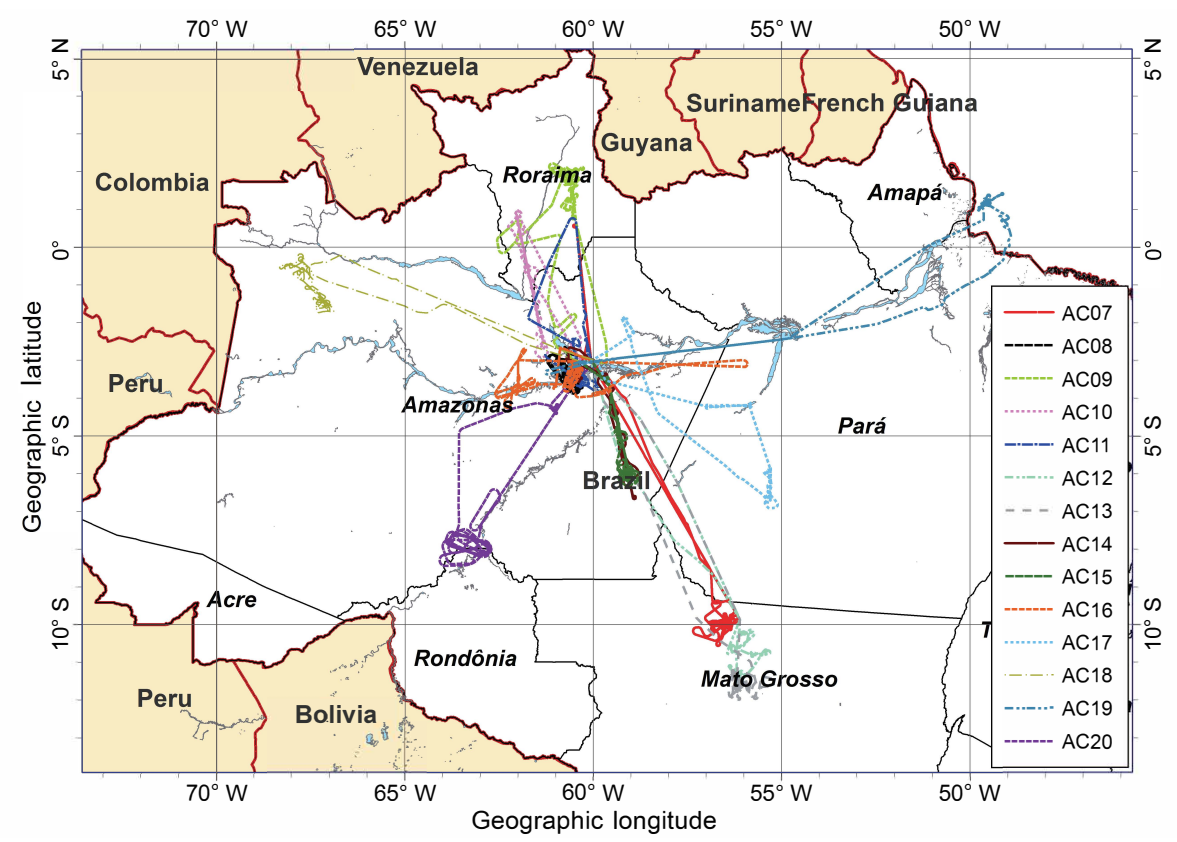

Figure 2. HALO flight tracks during the ACRIDICON-CHUVA experiment. The flight numbers are indicated on the right (from Wendisch et al., 2016).

used for this study. Section 3 gives an overview of the cloud probe measurements and discusses consistencies and disagreements between the measurements. Section 4 describes the methodologies applied to compare measurements and model results at cloud base.

\section{Instrumentation}

The HALO flights during the ACRIDICON-CHUVA campaign were performed over the Amazon region, centered on Manaus, during September 2014 under different conditions of aerosol concentration and land cover, as shown in Fig. 2 (from Wendisch et al., 2016). This region was chosen for documenting cloud microstructure and precipitation-forming processes during the dry season with high concentrations of $\mathrm{CCN}$ and to contrast these measurements with cleaner conditions that could be found within flight range, as documented previously (Andreae et al., 2004; Artaxo et al., 2002). Additionally, we made use of the fact that Manaus is located in the central Amazon $\left(3.11^{\circ} \mathrm{S}, 60.02^{\circ} \mathrm{W}\right)$, and the aerosol perturbation from the Manaus urban plume may therefore increase CCN concentrations by 1 to 2 orders of magnitude above the pristine conditions in the background air (Kuhn et al., 2010). This study is carried out in collaboration with the Green Ocean Amazon experiment GoAmazon (Martin et al., 2016), which also addressed the aerosol influences on cloud microphysical properties with a special focus on the Manaus urban plume. A comprehensive introduction to airborne instrumentation is given by Wendisch and Brenguier (2013), in particular the microphysical instruments involved in this study (Brenguier et al., 2013).

\subsection{CCN measurements}

$\mathrm{CCN}$ number concentrations were measured onboard HALO during ACRIDICON-CHUVA using a two-column CCNC (CCN-200; columns A and B), which is a continuous-flow longitudinal thermal-gradient instrument manufactured by Droplet Measurement Technologies (DMT) (Roberts and Nenes, 2005). It measures the CCN number concentration as a function of water vapor supersaturation $(S)$ at a time resolution of $1 \mathrm{~Hz}$. In the instrument, the sampled aerosol particles are exposed to a set supersaturation and adsorb water depending on their size and chemical composition. Particles that grow to droplets larger than $1 \mu \mathrm{m}$ in diameter are counted as $\mathrm{CCN}$ at that $S$. The instrument was calibrated between flights following Rose et al. (2008). The estimated uncertainty in CCN number concentration is about $20 \%(10 \%)$ on average for large (small) concentrations. In addition, the uncertainty in supersaturation values is $10 \%$ on average.

Sample air for the aerosol measurements was obtained from two different inlets: (i) the HALO aerosol submicron inlet (HASI) and (ii) the HALO counterflow virtual impactor (HALO-CVI) (Wendisch et al., 2016). The CCN-200 provides the possibility to measure from both inlets in parallel or at two different values of $S$. In this study, only the aerosol measurements from the HASI inlet have been used. The measurements were taken with one column at a constant 
$S=0.55 \%$, while the other cycled $S$ between 0.2 and $0.55 \%$ with steps every $100 \mathrm{~s}$.

\subsection{Cloud probe measurements}

Three cloud probes were operated onboard HALO during the measurements in the ACRIDICON-CHUVA campaign. This study focuses on the CAS-DPOL and CCP-CDP probes. The third probe, NIXE-CAS-DPOL, was of an identical type as CAS-DPOL and is thus not used in this study. The probe measurement range is shown in Table 1. In this study, cloud particle concentrations are counted at diameters larger than $3 \mu \mathrm{m}$ to avoid measurements of haze droplets. This is also in accordance with the similar lower limits of the bin sizes for the CCP-CDP. Details of the cloud probe measurement characteristics are described in the following sections (see also Brenguier et al., 2013).

\subsubsection{CCP-CDP and CCP-CIP measurements}

The cloud combination probe (CCP) combines two detectors, the cloud droplet probe (CDP) and the grayscale cloud imaging probe (CIPgs). The CDP detects forward-scattered laser light from cloud particles as they pass through the CDP detection area (Lance et al., 2010) and represents an advanced version of the forward scattering spectrometer probe (FSSP) (Baumgardner et al., 1985; Dye and Baumgardner, 1984; Korolev et al., 1985; Wendisch et al., 1996). The CIPgs records 2-D shadow-cast images of cloud elements that cross the CIPgs detection region. The overall particle detection size range is 2 to $960 \mu \mathrm{m}$ with the CCP. The highest temporal resolution of the CCP measurements is limited to $1 \mathrm{~Hz}$. Recent findings concerning the measurement uncertainties in the underwing cloud probes at the comparatively high HALO flight velocities (well above $170 \mathrm{~m} \mathrm{~s}^{-1}$ ) provide correction procedures to be applied to the measured raw data to further improve the data quality of the ambient cloud particle number concentrations (Weigel et al., 2016). The robust performance of the specific CCP instrument used in this study, even under extreme conditions, was demonstrated by earlier investigations in tropical convective outflow (Frey et al., 2011), polar stratospheric clouds (PSC) (Molleker et al., 2014), and low-level mixed-phase clouds in the Arctic (Klingebiel et al., 2015). For the data processing of the CIP measurements, ice is assumed as the predominant particle phase in the mixedstate cloud conditions that were mainly present throughout the ACRIDICON-CHUVA campaign. The assumption of ice density instead of water density implies a slight overestimation $(\sim 10 \%)$ of the calculated rainwater content for particles greater than $75 \mu \mathrm{m}$.

For the CDP sample area of $0.27 \mathrm{~mm}^{2}$, an uncertainty of about $10 \%$ was considered (Molleker et al., 2014). The uncertainty of $\pm 0.03 \mathrm{~mm}^{2}$ results from repeated measurements. Unless there is no massive manipulation or disarrangement of the CDP optics or a detectable aging of the laser diode,
Table 1. Cloud probe size intervals and central bin diameters during HALO flights.

\begin{tabular}{lccc}
\hline Cloud probe & $\begin{array}{c}\text { Size } \\
\text { interval }\end{array}$ & $\begin{array}{c}\text { Number } \\
\text { of bins }\end{array}$ & Central bin diameter $(\mu \mathrm{m})$ \\
\hline CCP-CDP & $3-50 \mu \mathrm{m}$ & 14 & $\begin{array}{c}3.8,6.1,8.7,10.9,13.5,17.1, \\
19.7,22.5,25.9,28.3,31.7, \\
36.6,40.7,44.2\end{array}$ \\
\hline CAS-DPOL & $3-50 \mu \mathrm{m}$ & 10 & $\begin{array}{c}3.9,6,10.8,17.3,22.3,27.4, \\
32.4,37.4,42.4,47.4\end{array}$ \\
\hline
\end{tabular}

the sample area remains stable even if the instrument experiences regular handling during, e.g., field campaign operations. Given the uncertainty in the sample area, the probe air speed (PAS), particle losses, deviations, and possibly the coincidence (not negligible, but likely not a significant issue), the uncertainty in cloud droplet concentration is below $20 \%$ and likely approaches or exceeds $20 \%$ only in cases of tight curve maneuvers; this might be the most prominent case when the "collecting angle" comes into play. For the flight pattern adopted during the vertical profiling of clouds (when cloud penetrations were performed during straight and level flight) the uncertainty in the number concentration for CCP-CDP is $10 \%$.

\subsubsection{CAS-DPOL measurements}

The CAS-DPOL measures particle size distributions between 0.5 and $50 \mu \mathrm{m}$ at $1 \mathrm{~Hz}$ of time resolution (Baumgardner et al., 2001). Its measurement principle is developed based on the FSSP-300 (Baumgardner et al., 1985; Korolev et al., 1985), which has been previously used to study the particle size range in ice clouds (Voigt et al., 2010, 2011; Schumann et al., 2011; Jeßberger et al., 2013). The intensity of forward-scattered light in the angular range of $4-12^{\circ}$ is detected and sorted into 30 size bins. Assuming Mie scattering theory, additional binning into 15 size bins is employed to rule out ambiguities. Polarized backward-scattered light is detected to investigate the sphericity and phase of the particles (Baumgardner et al., 2005; Gayet et al., 2012; Järvinen et al., 2016). Number concentrations are derived using the probe air speed measured by the probe. The distribution of time intervals between single particles, recorded for the first 290 particles in each second, did not provide indications of droplet coincidence up to a time resolution of $0.8 \mu$ s or a number concentration of $2200 \mathrm{~cm}^{-3}$. After the campaign, the sampling area (SA) used to derive the number concentration of particles was characterized by a high-resolution scan with a droplet generator. For this, 250 water droplets of a known, quasi-constant size of about $40 \mu \mathrm{m}$ were dropped at and around the sensitive region perpendicular to the laser beam. The resolution of the droplet generator scan was $25 \mu \mathrm{m}$ perpendicular to the laser beam and $50 \mu \mathrm{m}$ along the laser beam. According to the scan, the area of the measured SA 
for particle diameters above $3 \mu \mathrm{m}$ was $0.27 \mathrm{~mm}^{2}$, which is $8 \%$ higher than the initially reported SA by the manufacturer. The fringe of the area, a region in which particles are counted but with low efficiency, was about $0.032 \mathrm{~mm}^{2}$. This represents an uncertainty of $15 \%$ in the total SA. Additionally, we estimate an uncertainty in the particle velocity in the CAS sampling tube of $15 \%$, taking into account that particle velocities in the sampling tube may be slowed down or accelerated compared to open-path instruments or the Pitot tube velocities at the CAS. This results in a combined uncertainty in the number concentration of $21 \%$.

Calibrations with glass beads of four different sizes $(2,5$, 20 , and $42 \mu \mathrm{m}$ ) were performed between the flights to monitor the stability of the size bin classification. Differences in the refractive index can be accounted for with the method of Rosenberg et al. (2012). The size calibration was stable over the whole campaign. For the purpose of this study, the effective diameter range between 10 and $26 \mu \mathrm{m}$ was evaluated, which employed the lowest amplifier gain stage. For particles up to $20 \mu \mathrm{m}$ in size, the calibration did not show any size deviations from the expected values. Larger particles with diameters $>40 \mu \mathrm{m}$ were shifted towards smaller sizes by about $5 \mu \mathrm{m}$. We therefore estimate an uncertainty in particle size for particle diameters above $40 \mu \mathrm{m}$ on the order of 13 to $15 \%$; the estimate is less for smaller particles. The instrument had been previously installed on HALO and the DLR Falcon aircraft during the campaigns ML-CIRRUS (The Midlatitude Cirrus; Voigt et al., 2017), ACCESS II (Alternative Fuel Effects on Contrails and Cruise Emissions; Moore et al., 2017), and DACCIWA (Dynamics-Aerosol-Chemistry-Cloud Interactions in West Africa; Knippertz et al., 2015).

\subsection{Hot-wire CWC measurements}

The hot-wire instrument is a King-probe-type device that measures the bulk liquid water content (LWC) from 0.01 to $3 \mathrm{~g} \mathrm{~m}^{-3}$ in the droplet diameter range of 5 to $50 \mu \mathrm{m}$ by detecting the power (current) required to maintain a heated wire at a constant temperature of $125^{\circ} \mathrm{C}$. The sensitivity of the instrument is reduced for droplets below $10 \mu \mathrm{m}$, since smaller particles more closely follow the streamlines around the hot wire. The instrument was mounted on the CASDPOL probe. The accuracy of the King probe LWC measurement is estimated to be $5 \%$ at $1 \mathrm{~g} \mathrm{~m}^{-3}$ and decreases to $16 \%$ at $0.2 \mathrm{~g} \mathrm{~m}^{-3}$ with a sensitivity of $0.02 \mathrm{~g} \mathrm{~m}^{-3}$ (King et al., 1978). For this study, mainly CWC values in the range up to $1 \mathrm{~g} \mathrm{~m}^{-3}$ were used.

\subsection{Vertical wind speed measurements}

The HALO aircraft was equipped with a new meteorological sensor system (BAsic HALO Measurement And Sensor System; BAHAMAS) located at the nose of the aircraft (Wendisch et al., 2016). Measurements of updraft speeds during cloud base penetrations during the ACRIDICON-
CHUVA campaign showed maximum vertical wind speeds in the range of $5 \mathrm{~m} \mathrm{~s}^{-1}$. In these conditions, the uncertainties in $W$ measurements are $0.3 \mathrm{~m} \mathrm{~s}^{-1}$ (Mallaun et al., 2015).

\section{Cloud probe intercomparison}

\subsection{Methods}

The validation of convective cloud parameterizations requires reliable cloud probe measurements. In this section, we quantitatively discuss the differences in the estimated and directly measured CWC and DSDs of the two cloud probes CAS-DPOL and CCP-CDP as well as the hot-wire instrument.

For comparisons between the CWC estimated from the cloud probe DSDs and hot-wire measurements $\left(\mathrm{CWC}_{h}\right)$, we distinguish between spectra that are dominated by condensational growth and spectra for which coalescence becomes important as well. These spectra are separated by the threshold of $r_{\mathrm{e}}$ for significant coalescence, which varies as a function of the drizzle water content (DWC) for $1 \mathrm{~s}$ cloud passes (Freud and Rosenfeld, 2012). In addition, droplets with diameters $<10 \mu \mathrm{m}$ are captured less efficiently by the hot-wire probe, resulting in an underestimation of $\mathrm{CWC}_{\mathrm{h}}$. The hotwire device was installed on the CAS-DPOL probe; therefore a better statistical agreement is expected for this probe in comparison with the CCP-CDP. The CCP-CDP was mounted on the other wing about $15 \mathrm{~m}$ from the hot-wire device (Voigt et al., 2017; Wendisch et al., 2016). Only cloud passes at temperatures greater than $0{ }^{\circ} \mathrm{C}$ are considered in this intercomparison to avoid uncertainties in the measurements due to the freezing of droplets.

\subsection{CWC comparison between cloud probe and hot-wire measurements}

A comparison of different techniques for cloud water content measurements is challenging because of the individual instrumental differences, like time resolution, dependence of sensitivity on size, and the characteristics of the target of interest, i.e., inhomogeneous, turbulent convective cloud.

For this study we use the hot-wire instrument as a reference to the scattering spectrometer probes, since its total water content is derived from a smaller set of physical parameters with an overall maximum uncertainty of $16 \%$ compared to $\sim 30 \%$ uncertainty when derived from DSDs.

The calculation of CWC is performed separately from CAS-DPOL and CCP-CDP probe droplet concentrations as follows:

$\mathrm{CWC}=\frac{4 \pi}{3} \rho \int N_{\mathrm{d}}(r) r^{3} \mathrm{~d} r$,

where $N_{\mathrm{d}}$ is the droplet concentration in $\mathrm{m}^{-3}, r$ is the droplet radius in $\mathrm{m}$, and $\rho$ is the water density $\left(1 \mathrm{~g} \mathrm{~cm}^{-3}\right)$. The calculation of DWC is similar to CWC but with different particle 


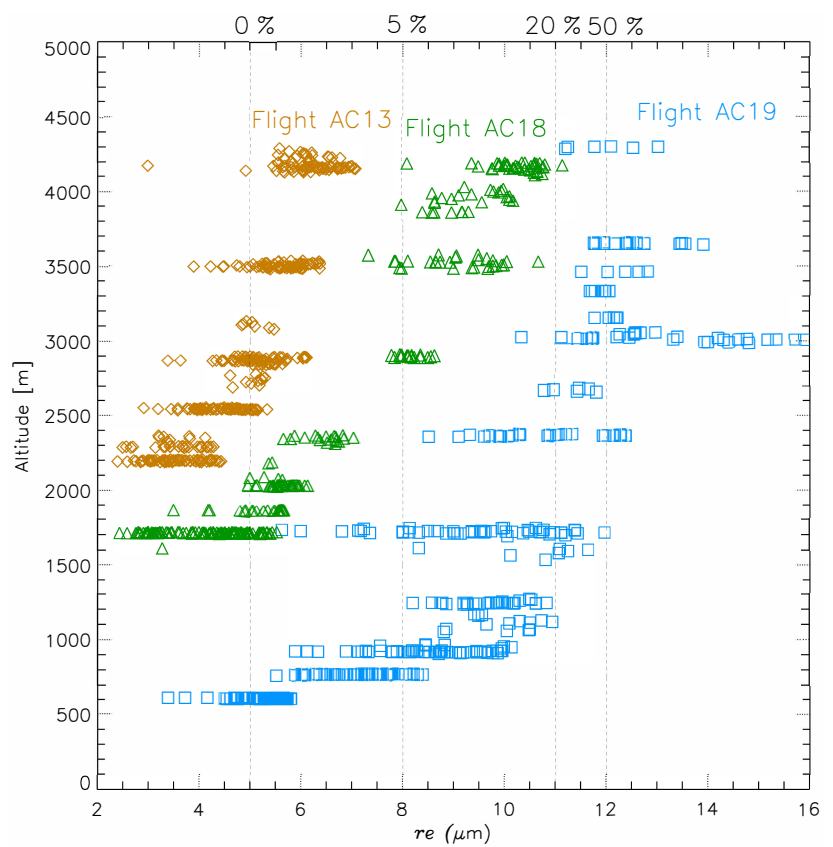

Figure 3. Cloud droplet effective radius $\left(r_{\mathrm{e}}\right)$ as a function of altitude for clouds over clean (Flight AC19; blue squares), polluted (Flight AC18; green triangles), and very polluted (Flight AC13; brown diamonds) environments. The dashed lines indicate the probability of rain from the coalescence process expressed as a percentage on the top of the figure.

size ranges from CCP-CIP measurements. The DSDs from CCP-CDP and CAS-DPOL are used to calculate the CWC, defined here as the mass of the drops integrated over the diameter range of $3-50 \mu \mathrm{m}$. Similarly, DSDs from CCP-CIP are used to calculate the DWC, defined here as the mass of the drops integrated over the diameter range of $75-250 \mu \mathrm{m}$ (Freud and Rosenfeld, 2012).

Figure 3 shows the dependency of calculated $r_{\mathrm{e}}$ as a function of altitude for cloud passes during flights over different aerosol concentration conditions (AC13 very polluted, $\mathrm{AC} 18$ polluted, and AC19 clean). The probability of rain due to collision and coalescence processes is indicated with dashed lines. It is assumed that rain formation starts when calculated DWC exceeds $0.01 \mathrm{~g} \mathrm{~m}^{-3}$ (Freud and Rosenfeld, 2012). Overall, the figure shows that $r_{\mathrm{e}}$ values increase with altitude. In addition, it shows the effects of aerosol loading, which in higher concentrations nucleates a larger number of droplets at cloud base that grow slower as a function of height via condensation. Also, for $r_{\mathrm{e}}$ values $<9 \mu \mathrm{m}$ the probability of droplet coalescence is very small and starts to be significant only for $r_{\mathrm{e}}>11 \mu \mathrm{m}$. There is little concern that raindrops precipitate from above when flights pass near the tops of growing convective clouds (as illustrated in Fig. 1).

The comparison of CWC estimated from the cloud probe data and $\mathrm{CWC}_{\mathrm{h}}$ measured with the hot wire was performed as a function of $r_{\mathrm{e}}$; this is because the measurement effi-
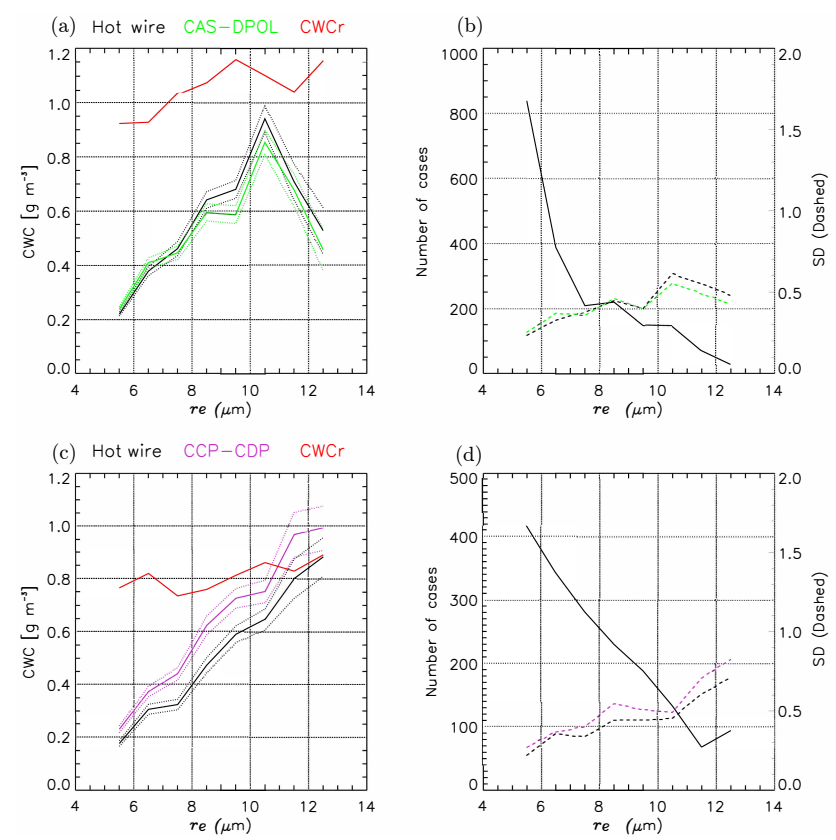

Figure 4. Mean cloud water content from the hot-wire measurements and estimated from the cloud probes (CCP-CDP and CASDPOL) as a function of effective radius $\left(r_{\mathrm{e}}\right)$ size $(\mathbf{a}, \mathbf{c})$. The ratios between the hot-wire liquid water content and the cloud water content derived from each probe are shown in red (CWCr). The total uncertainties for each probe and the hot-wire measurements are shown by the dotted lines. The number of cases (black continuous line), hot-wire measurement standard deviations (dashed black line), and probe CWC standard deviations (dashed colored line) for each $r_{\mathrm{e}}$ size are also shown $(\mathbf{b}, \mathbf{d})$.

ciency of the hot-wire probe depends on drop size. This type of analysis also provides information about the differences between the two cloud probes regarding the estimated CWCs. Strapp et al. (2003) show that large differences between actual CWC and hot-wire measurements occur when larger drops $(\sim r>20 \mu \mathrm{m})$ contribute to the cloud water content above $1 \mathrm{~g} \mathrm{~m}^{-3}$. We therefore limit our analysis to the effective diameter range of $5 \mu \mathrm{m}<r_{\mathrm{e}}<13 \mu \mathrm{m}$ and compare $\mathrm{CWC}_{\mathrm{h}}$ with $\mathrm{CWC}$ estimated from the cloud probe DSD only for CWC up to $1 \mathrm{~g} \mathrm{~m}^{-3}$. The comparison between the mean CWC estimated from the cloud probe DSDs and mean $\mathrm{CWC}_{\mathrm{h}}$ is shown as a function of $r_{\mathrm{e}}$ in Fig. 4. The ratio between the $\mathrm{CWC}_{\mathrm{h}}$ from the hot-wire measurements and the probe estimates (CWCr) is also shown (in red).

The mean values of $\mathrm{CWC}$ estimated from the probes from flights AC08 to AC20 (AC07 had no hot-wire CWC data) at altitudes between 600 and $5000 \mathrm{~m}$ generally show an increase with increasing $r_{\mathrm{e}}$. The CWC uncertainty calculated with CAS-DPOL (CCP-CDP) DSDs is about $22 \%(10 \%)$ for all measurements. In addition, the uncertainty associated with $r_{\mathrm{e}}$ calculations with CAS-DPOL (CCP-CDP) DSDs is about $14 \%(9 \%)$. Within their statistical variability, the CAS-DPOL CWC agrees well with the hot-wire $\mathrm{CWC}_{\mathrm{h}}$ over 
the whole effective radius range (upper panel). The $\mathrm{CWCr}$ for CAS-DPOL (CCP-CDP) is around $1 \pm 0.1(0.8 \pm 0.05)$ for almost all $r_{\mathrm{e}}$ sizes. The comparisons of the $\mathrm{CWC}_{\mathrm{h}}$ with the CWC estimated from the CCP-CDP probe (lower panel) shows that the CCP-CDP is systematically higher by about $21 \%$. The difference is larger than the standard deviation of the individual measurements. The overall systematic differences (mean of the ratio) in the cloud probe CWC in comparison to $\mathrm{CWC}_{\mathrm{h}}$ are $0.04 \mathrm{~g} \mathrm{~m}^{-3}(6 \%)$ for CAS-DPOL and $0.11 \mathrm{~g} \mathrm{~m}^{-3}(21 \%)$ for CCP-CDP higher than the hot-wire measurements. However, considering the uncertainty in the measurements, all three CWC measurements agree within the uncertainty range (16 and $30 \%$ ).

In summary, the $\mathrm{CWC}_{\mathrm{h}}$ from the hot wire agrees better with the CWC derived from CAS-DPOL DSDs. The fact that the CCP-CDP was mounted on the opposite wing while the measurements were performed in very inhomogeneous conditions may account for some of the larger spread between CCP-CDP and the hot wire than between CAS-DPOL and the hot wire (e.g., in $r_{\mathrm{e}}$ ), but it cannot explain the systematic offset of the CCP-CDP. In the next subsection we discuss the input parameters for the CWC estimated from the cloud probes, like number concentration and size, to find an explanation for the observed differences.

\subsection{Comparing cloud probe $N_{\mathrm{d}}$ and DSDs}

Figure 5 shows the mean $N_{\mathrm{d}}$ values measured by CAS-DPOL and CCP-CDP (solid line) and the systematic uncertainties in the measurements (dashed lines) as a function of $r_{\mathrm{e}}$ for values greater than $5 \mu \mathrm{m}$ (left panel) and the standard deviation of the two cloud probe $N_{\mathrm{d}}$ measurements (right panel). The data are the same as those used for the hot-wire intercomparison. Both probes measure a decreasing number concentration with an increasing effective radius and $\mathrm{CWC}$ at greater heights above cloud base. This is related to the increasing extent of mixing and coalescence processes with height in the cloud. Therefore, a reduced number of larger droplets contributes to the enhanced CWC at larger $r_{\mathrm{e}}$. In general, the CAS-DPOL mean $N_{\mathrm{d}}$ agrees well (difference lower than $1 \%$ ) with the mean $N_{\mathrm{d}}$ of CCP-CDP for effective radii between 7 and $11 \mu \mathrm{m}$. Statistically significant differences are observed for $r_{\mathrm{e}}$ smaller than $7 \mu \mathrm{m}$ and above $11 \mu \mathrm{m}$. Both probes have a similar standard deviation (SE) for different $r_{\mathrm{e}}$ sizes. The SE decreases with increasing $r_{\mathrm{e}}$, varying from $\sim 20$ to $\sim 10 \mathrm{~cm}^{-3}$.

The two $N_{\mathrm{d}}$ measurements agree within the combined statistical variability and the systematic uncertainties in the two probe measurements (21\% for CAS-DPOL and $10 \%$ for CCP-CDP). However, in order to explain the difference in $\mathrm{CWC}$, we point to the difference in the mean droplet number at $r_{\mathrm{e}}>11 \mu \mathrm{m}$. Lower number concentrations of the CASDPOL at larger $r_{\mathrm{e}}$ may be related to the shift in droplet radii for particles above $40 \mu \mathrm{m}$ to smaller sizes, which shifts the effective radius and the CWC to smaller $r_{\mathrm{e}}$ and smaller $\mathrm{CWC}$.
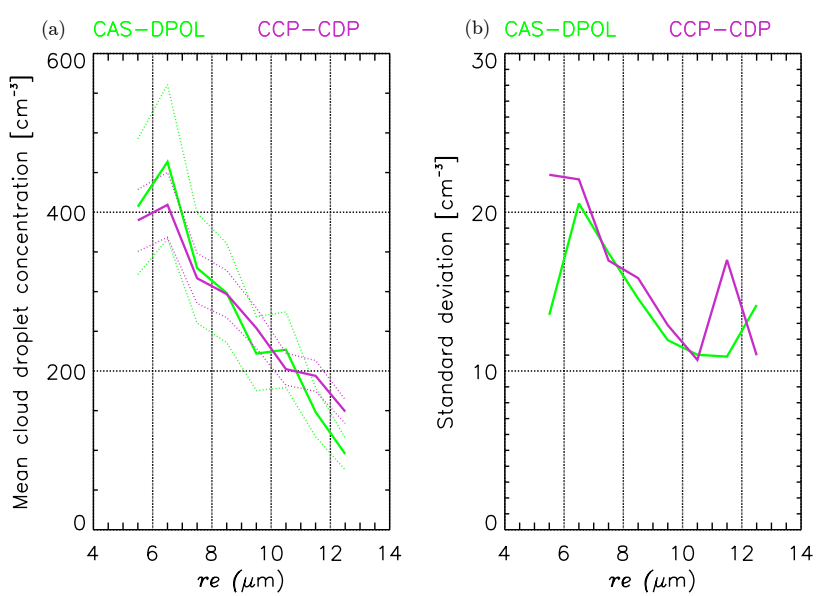

Figure 5. Mean cloud droplet concentrations for CAS-DPOL and CCP-CDP as a function of effective radius $\left(r_{\mathrm{e}}\right)(\mathbf{a})$. The systematic error for each probe is shown by the dashed line. (b) The standard deviation in $\mathrm{cm}^{-3}$ of each probe concentration as a function of $r_{\mathrm{e}}$. The probes are identified by colors as shown at the top of the panels. The sample for each probe is the same as shown in Fig. 4.

On the other hand, the difference in the size binning of the two probes may artificially shift particles from larger sizes to smaller sizes based only on the choice of the bin boundaries. For the CAS-DPOL, larger bin sizes were chosen in order to avoid ambiguities based on Lorenz-Mie theory.

The differences in $N_{\mathrm{d}}$ at larger $r_{\mathrm{e}}$ correspond to the enhanced CWC in Fig. 4 and may explain most of the differences in $\mathrm{CWC}$ between the probes. The higher number concentration at $r_{\mathrm{e}}<7 \mu \mathrm{m}$ may be explained by the higher sensitivity and lower cutoff of the CAS-DPOL at smaller sizes. The instrument was built to particularly measure the full spectrum of aerosol and cloud particles in the size range in which aerosols are activated into cloud droplets.

Figure $6 \mathrm{a}-\mathrm{d}$ show the mean droplet concentration and $\mathrm{CWC}$ as a function of droplet diameter from the cloud probes. The distributions are shown for four different effective radii to give an impression of the evolution of particle size and CWC with altitude for the two cloud probes. For $r_{\mathrm{e}}$ between 5 and $6 \mu \mathrm{m}$ and 8 and $9 \mu \mathrm{m}$ (Fig. $6 \mathrm{a}$ and b), at which collision and coalescence processes are negligible (see Fig. 3), the CCP-CDP DSDs are somewhat below the CASDPOL DSDs, revealing an enhanced sensitivity of the CASDPOL for smaller particles. For larger $r_{\mathrm{e}}$ (Fig. 6c and d), at which coalescence starts and raindrops may be present, the CCP-CDP shows slightly larger droplet concentrations and CWC for diameters $>15 \mu \mathrm{m}$ in comparison to CAS-DPOL. This may be related to larger droplets that enter the open-path instrument sampling area of the CCP-CDP more easily than the closed-path sampling area of the CAS-DPOL by falling vertically into the measurement area.

These results suggest that CAS-DPOL and CCP-CDP generally measure similar droplet concentrations in the size 

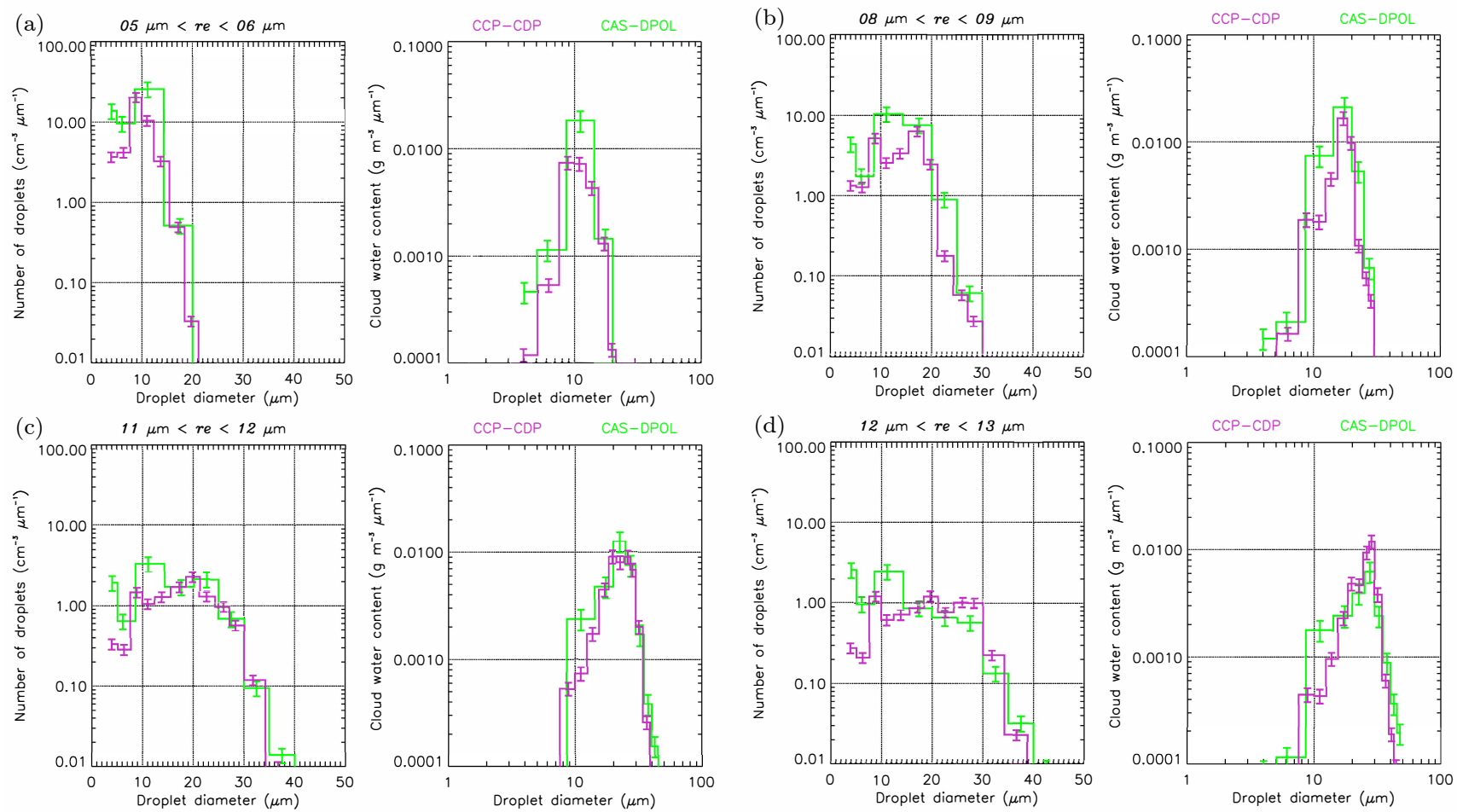

Figure 6. Mean cloud droplet concentration (solid lines) and cloud water content as a function of droplet diameter in the left and right panels, respectively, for (a) $5 \mu \mathrm{m}<r_{\mathrm{e}}<6 \mu \mathrm{m}$, (b) $8 \mu \mathrm{m}<r_{\mathrm{e}}<9 \mu \mathrm{m}$, (c) $11 \mu \mathrm{m}<r_{\mathrm{e}}<12 \mu \mathrm{m}$, and (d) $12 \mu \mathrm{m}<r_{\mathrm{e}}<13 \mu \mathrm{m}$. The probes are identified by colors as shown at the top of the panels. The error bars indicate the uncertainty range of mean cloud droplet concentration and cloud water content values as a function of droplet diameter.

range between 3 and $50 \mu \mathrm{m}$. The observed deviations between the probes could be caused by different inlet configurations or measurement principles for the two probes, each with individual advantages depending on the measurement target and related size range. However, the differences in DSDs are within the uncertainties in the measurement and show a much better agreement than earlier measurements under similar conditions (Lance, 2012; Rosenberg et al., 2012).

\section{Methodology}

The reliability of the cloud probe measurements demonstrated in the previous section provides the capability to perform the validation of convective cloud parameterizations for the Amazon region; these analyses are performed through the following four steps. Section 4.1 presents the analyses of CCN measurements below cloud base. Assuming that the relation between $N_{\mathrm{CCN}}$ and $S$ is given by Eq. (1), the parameters $N_{0}$ and the slope $k$ are calculated from the measurements below cloud base. Section 4.2 describes the estimation of maximum $S$ at cloud base ( $\left.S_{\max }\right)$ based on the measured $N_{\mathrm{d}}$ and $W_{\mathrm{b}}$ there. The covariability of $N_{\mathrm{d}}$ and $W_{\mathrm{b}}$ is used to estimate the CCN concentration $\left(N_{\mathrm{dCCN}}\right)$ by calculating $S_{\max }$ according to Eq. (1). This is repeated for the two $N_{\mathrm{d}}$ spec- tra that were obtained from the two cloud droplet probes. In addition, $N_{\mathrm{d}}$ is estimated through the application of the measured $W_{\mathrm{b}}$ spectrum to Eq. (2) and a comparison against the directly measured $N_{\mathrm{d}}$ from the two cloud probes. Section 4.3 outlines the methodology for calculating the effective number of droplets at cloud base from cloud probe measurements $\left(N_{\mathrm{d}}^{*}\right)$. This is done using theoretical considerations based on the estimated values of $N_{\mathrm{dT}}$ and $N_{\mathrm{dCCN}}$ at cloud base ( $N_{\mathrm{dT}}^{*}$ and $N_{\mathrm{dCCN}}^{*}$, respectively). The exact definitions of all parameters are provided in Sect. 4.2. Section 4.4 explains the calculation of the estimated adiabatic cloud droplet concentration $\left(N_{\mathrm{a}}\right)$, as obtained from the measured vertical profile of cloud drop size distributions.

\subsection{CCN measurements below cloud base as a function of $S$}

The measurements of $N_{\mathrm{CCN}}$ and $S$ can be parameterized by Eq. (1) and provide $N_{0}$ and $k$ (Pruppacher et al., 1998). The typical values of $N_{0}$ are about $100 \mathrm{~cm}^{-3}$ for pristine conditions and range from $500 \mathrm{~cm}^{-3}$ to several thousand $\mathrm{cm}^{-3}$ for polluted continental regions at different levels of aerosol loading. The values of the slope parameter $k$ vary from about 0.3 to 1 in clean and polluted air, respectively (Andreae, 2009). 
Two types of $\mathrm{CCN}$ measurements were performed: (i) measuring $\mathrm{CCN}$ concentration at fixed $S(\sim 0.55 \%$; hereafter referred to as $S_{1}$ with the corresponding CCN concentration referred to as $\mathrm{CCN}_{1}$ ) and (ii) measuring $\mathrm{CCN}$ concentration at variable $S$ (ranging from 0.2 to $0.55 \%$; hereafter referred to as $S_{2}$ with the corresponding $\mathrm{CCN}$ concentration referred to as $\mathrm{CCN}_{2}$ ). Since the $\mathrm{CCN}_{2}$ measurements were performed at varying $S_{2}$ (generally modified every 100 s during the flights; hereafter referred to as a time step), the mean values of these measurements for each time step are used to calculate the $N_{0}$ and $k$ parameters in Eq. (1). The flight period of measurements below cloud base in a specific region consisted of several CCN time steps, covered at least one full $N_{\mathrm{CCN}}(S)$ spectrum, and is defined as a group of measurements (hereafter referred to as a group).

To achieve accurate measurements of $\mathrm{CCN}_{2}$ as a function of $S_{2}$, a weighting factor calculated from the $\mathrm{CCN}_{1}$ measurements is applied, as specified in the steps below. Because $\mathrm{CCN}_{1}$ measures at a fixed supersaturation $\left(S_{1}\right)$, its variability is caused only by changes in total $\mathrm{CCN}$ concentration (from aerosol loading) along the flight track (assuming constant size distribution and composition during the measurement group). This is used to correct the $N_{\mathrm{CCN}}(S)$ as measured by $\mathrm{CCN}_{2}$ for these changes in total concentration. The procedure for this analysis is described below.

1. The mean values of $S_{1}, S_{2}, \mathrm{CCN}_{1}$, and $\mathrm{CCN}_{2}$ measurements $\left(\mathrm{mS}_{1}, \mathrm{mS}_{2}, \mathrm{mCCN}_{1}\right.$, and $\mathrm{mCCN}_{2}$, respectively) are calculated for each time step below cloud base.

2. An aerosol loading factor (FA) for measurements during a full cycle of $S$ is calculated as follows:

$\mathrm{FA}=\frac{\mathrm{mCCN}_{1}}{\mathrm{TmCCN}_{1}}$

where $\mathrm{TmCCN}_{1}$ is the mean of all $\mathrm{CCN}_{1}$ measurements for the group of $S$ cycling. FA provides the deviation in aerosol concentration from the mean for a specific time step in the group.

3. The mCCN2 values for each group are weighted by FA-generating normalized $\mathrm{mCCN}_{2}$ values $\left(\mathrm{NCCN}_{2}=\mathrm{mCCN}_{2} / \mathrm{FA}\right)$. Then, the $\mathrm{NCCN}_{2}$ values are used in combination with $\mathrm{mS}_{2}$ to fit a power-lawfunction equation for each group of measurements. From this fit, the values of the parameters $N_{0}$ and $k$ in the Twomey equation $\left(N_{\mathrm{CCN}}=N_{0} \cdot S^{k}\right)$ are obtained.

\subsection{Estimating $S_{\mathrm{max}}, N_{\mathrm{dCCN}}$, and $N_{\mathrm{dT}}$}

The number of CCN that nucleate into cloud droplets $\left(N_{\mathrm{d}}\right)$ reaches its maximum value near the $S_{\max }$ height in the cloud (Pinsky et al., 2012). This level is observed between cloud base and a height up to a few tens of meters above it. The value of $S_{\max }$ can be estimated from Eq. (3) based on the vertical velocity at cloud base and on $N_{\mathrm{d}}$ as measured with the cloud probes CCP-CDP and CAS-DPOL (Ncdp and Ncas, respectively). Therefore, the estimated $S_{\max }$ near cloud base can be used in Eq. (1) to produce the $N_{\mathrm{dCCN}}$ estimates to hopefully achieve a closure for the $N_{\mathrm{d}}$ measurements at cloud base.

The $N_{0}$ and $k$ values that were calculated from measurements below cloud base (as described in Sect. 4.1) are substituted in Eqs. (1) and (2) to calculate $N_{\mathrm{dCCN}}$ and $N_{\mathrm{dT}}$, respectively. The comparisons between $N_{\mathrm{dCCN}}, N_{\mathrm{dT}}$, and $N_{\mathrm{d}}$ from the cloud probes are discussed in Sect. 5.2. Measurements of $N_{\mathrm{d}}$ for each probe are considered only for concentrations $\geq 20$ droplets per cubic centimeter to focus on the convective elements and avoid highly mixed and dissipating portions of the clouds. The time and distance differences that were allowed between the measurements below cloud base and at cloud base have maximum values of $1 \mathrm{~h}$ and $30 \mathrm{~km}$, respectively. With this consideration, we assume that the $N_{\mathrm{d}}$ measurements at cloud base pertain to the same region as the CCN measurements below cloud base.

According to Twomey (1959), the $N_{\mathrm{d}}$ that should be observed at cloud base increases with $W_{\mathrm{b}}$ (assuming a constant CCN concentration; see Eq. 2). However, at cloud base the variability in $W_{\mathrm{b}}$ and $N_{\mathrm{d}}$ measurements is high due to air turbulence. Since a cloud parcel moves as an eddy with a local $W_{\mathrm{b}}$ that produces a given $N_{\mathrm{d}}$ at cloud base, its continued movement as a turbulent eddy within the cloud adds a large random component to the individual realizations of $W_{\mathrm{b}}$ for a given $N_{\mathrm{d}}$. These turbulent characteristics greatly reduce the confidence that a given measured $W_{\mathrm{b}}$ within the cloud has produced the corresponding measured $N_{\mathrm{d}}$; therefore, these measurements are often not well correlated. A suitable method to analyze the relationship between $W_{\mathrm{b}}$ and $N_{\mathrm{d}}$ measurements is the "probability matching method" (PMM) (Haddad and Rosenfeld, 1997), which requires that the two related variables increase monotonically with each other. For a set of $W_{\mathrm{b}}$ and $N_{\mathrm{d}}$ measurements at cloud base, it is expected that larger $W_{\mathrm{b}}$ would produce larger $N_{\mathrm{d}}$ for a given $N_{\mathrm{CCN}}(S)$. Therefore, it is also assumed that $N_{\mathrm{d}}$ is produced uniquely by $W_{\mathrm{b}}$ for a given $N_{\mathrm{CCN}}(S)$ spectrum as calculated from the measurements below cloud base. It is further assumed that entrainment does not change systematically with $W_{\mathrm{b}}$ in a way that would reverse the monotonic increase of $W_{\mathrm{b}}$ with $N_{\mathrm{CCN}}(S)$. In a PMM analysis, the same percentiles of updrafts are matched to the same percentiles of $N_{\mathrm{d}}$ (or $N_{\mathrm{dCCN}}$ and $N_{\mathrm{dT}}$ ). As $N_{\mathrm{d}}$ must be produced by positive updrafts (Eq. 2), negative (positive) values of $W_{\mathrm{b}}$ are associated with lower (higher) $N_{\mathrm{d}}$. This procedure allows for the identification of the role of $W_{\mathrm{b}}$ (positive) in producing $N_{\mathrm{d}}$ in a set of cloud base measurements. The results of PMM analysis from cloud probes $N_{\mathrm{d}}$ vs. $W_{\mathrm{b}}$ and for estimated $N_{\mathrm{dCCN}}$ with $N_{\mathrm{dT}}$ are discussed in Sect. 5.2.1. 


\subsection{Estimating $W_{\mathrm{b}}^{*}, N_{\mathrm{d}}^{*}, N_{\mathrm{dT}}^{*}$, and $N_{\mathrm{dCCN}}^{*}$}

The formulation of an effective updraft speed at cloud base $\left(W_{\mathrm{b}}^{*}\right)$ is a useful approximation of the updraft spectrum (Rosenfeld et al., 2014a; Zheng et al., 2015). $W_{\mathrm{b}}^{*}$ and $N_{\mathrm{d}}^{*}$ are given in Eqs. (6) and (7):

$W_{\mathrm{b}}^{*}=\frac{\int W_{\mathrm{b}}^{2}}{\int W_{\mathrm{b}}} ;$ where $W_{\mathrm{b}}>0$,

$N_{\mathrm{d}}^{*}=N_{\mathrm{d}}\left[\operatorname{percentile}\left(W_{\mathrm{b}}^{*}\right)\right]$,

where $N_{\mathrm{d}}^{*}$ represents the spectrum of $N_{\mathrm{d}}$ at cloud base that matches the same percentile of $W_{\mathrm{b}}^{*}$. Figure 7 shows an illustration and example of the estimated values of $W_{\mathrm{b}}^{*}$ and $N_{\mathrm{d}}^{*}$ from the CCP-CDP probe for flight AC17. In this case, the calculated $W_{\mathrm{b}}^{*}$ has a value of $1.83 \mathrm{~m} \mathrm{~s}^{-1}$, which represents the 86th percentile of total measurements at cloud base when sorted by $W_{\mathrm{b}}$ measurements, including negative values. The corresponding percentile of $N_{\mathrm{d}}^{*}$ (when sorted by $N_{\mathrm{d}}$ ) is $1207 \mathrm{~cm}^{-3}$. Another approach to $N_{\mathrm{d}}$ retrieval is the calculation of $N_{\mathrm{dT}}^{*}$ considering $W_{\mathrm{b}}^{*}$ as the updraft wind speed in Eq. (2). In addition, $S_{\max }$ can be estimated by applying the calculated values of $W_{\mathrm{b}}^{*}$ and $N_{\mathrm{d}}^{*}$ to Eq. (3). Then, applying the obtained $S_{\max }$ to Eq. (1) yields $N_{\mathrm{dCCN}}^{*}$. The values of the calculated $N_{\mathrm{dT}}^{*}$ and $N_{\mathrm{dCCN}}^{*}$ are 1175 and $915 \mathrm{~cm}^{-3}$, respectively.

\subsection{Estimating $N_{\mathrm{a}}$}

Another approach to estimating $N_{\mathrm{d}}$ is through the calculation of the adiabatic cloud droplet number concentration, $N_{\mathrm{a}}$ (Freud et al., 2011). The $N_{\mathrm{a}}$ is calculated from CWC and the mean volume droplet mass $\left(M_{\mathrm{V}}\right)$ from the cloud probe DSDs obtained during the cloud-profiling measurements. This behavior is the outcome of the almost completely inhomogeneous mixing behavior of the clouds with the ambient air (Burnet and Brenguier, 2007; Freud et al., 2011). Recently, Beals et al. (2015) wrote that their "measurements reveal that turbulent clouds are inhomogeneous, with sharp transitions between cloud and clear air properties persisting to dissipative scales $(<1 \mathrm{~cm})$. The local droplet size distribution fluctuates strongly in number density but with a nearly unchanging mean droplet diameter". The dominance of inhomogeneous mixing diminishes when the drops become very large $\left(r_{\mathrm{e}}>15 \mu \mathrm{m}\right)$ and their evaporation rate becomes more comparable to the mixing rate. This is most evident in cloud passes during which CWC is greater than $25 \%$ of the adiabatic CWC (Freud et al., 2011). The measurements during cloud-profiling flights were aimed at penetrating the tops of growing convective towers (as shown in Fig. 1). This was done successfully in the data selected for analysis, as verified by the examination of videos recorded by the HALO cockpit camera. The cloud penetrations occurred mainly near the tops of growing convective cumulus, where mixing is expected to be rather inhomogeneous and little precipitation (a) Time: 17:18 (102 s) Flight: AC17

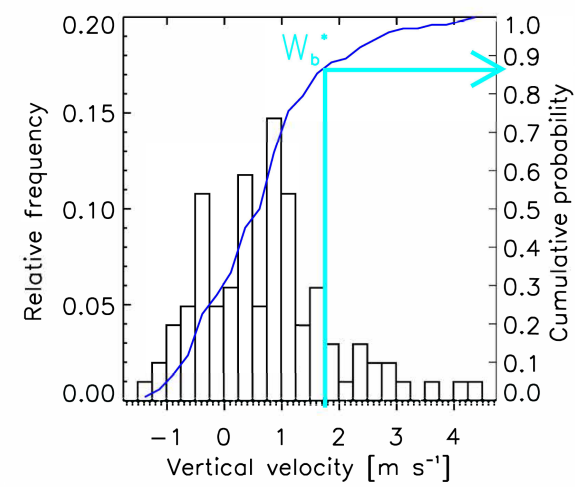

(b)

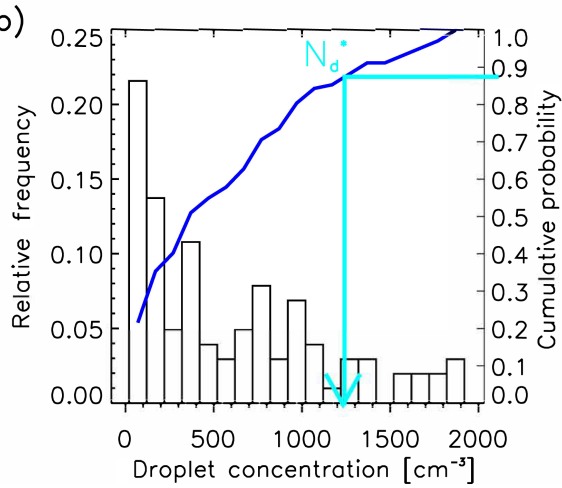

Figure 7. (a) Frequency histogram of vertical wind speed $\left(W_{\mathrm{b}}\right)$ from cloud base measurements on flight AC17 (labeled on the left ordinate). The blue line indicates the cumulative probability function of $W_{\mathrm{b}}$ (labeled on the right ordinate). The cyan arrow indicates the value of $W_{b}^{*}\left(1.83 \mathrm{~m} \mathrm{~s}^{-1}\right)$ that represents the 86th percentile of the $W$ spectra. (b) A similar histogram for the cloud droplet concentrations measured with the CCP-CDP probe. The cyan line indicates the $N_{\mathrm{d}}^{*}$ value $\left(1207 \mathrm{~cm}^{-3}\right)$ at the 86 th percentile in the $N_{\mathrm{d}}$ spectra. The indicated time is in UTC and shows the time of the first cloud penetration at cloud base and the total number of $1 \mathrm{~s}$ measured cloud data points.

can fall from above. The validity of this expectation will affect the agreement between $N_{\mathrm{d}}$ and $N_{\mathrm{a}}$. The $N_{\mathrm{a}}$ is calculated from the slope of CWC and $M_{\mathrm{v}}$ measurements and provides an estimate of $N_{d}^{*}$ near cloud base. However, this methodology does not account for cloud mixing losses from droplet evaporation, and the $N_{\mathrm{a}}$ estimates commonly overestimate the expected $N_{\mathrm{d}}$ by $30 \%$ (Freud et al., 2011). Therefore, in calculating $N_{\mathrm{a}}$ we applied this $30 \%$ correction.

\section{Results}

\subsection{CCN measurements below cloud base}

The estimation of the $N_{0}$ and $k$ parameters in Eq. (1) is made from CCN and $S$ measurements below cloud base. Figure 8 illustrates CCN and $S$ measurements below cloud base for flight $\mathrm{AC} 17$ over a deforested region in the central 


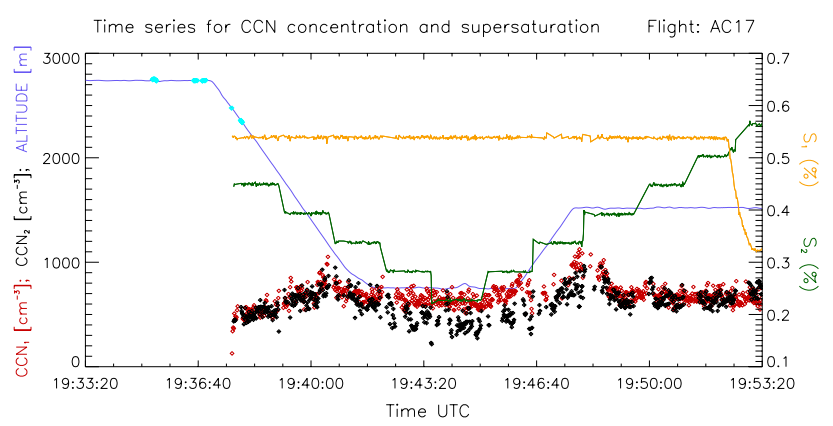

Figure 8. $\mathrm{CCN}_{1}$ (red dots) and $\mathrm{CCN}_{2}$ (black dots) measurements for a segment of flight AC17 on 27 September 2014. The abscissa shows the measurement time in UTC. The blue line indicates the altitude in meters above sea level and is labeled on the left ordinate (along with $\mathrm{CCN}_{1}$ and $\mathrm{CCN}_{2}$ ). $S_{1}$ and $S_{2}$ measurements in $\%$ are indicated by the orange and green lines, respectively (both are labeled on the right ordinate). The cyan dots on the blue line indicate cloud penetrations (i.e., when cloud droplet concentrations are greater than $20 \mathrm{~cm}^{-3}$ ). In this case, cloud base heights were observed around $2300 \mathrm{~m}$ above ground.

Amazon. The cloud base was located at a height of about $2300 \mathrm{~m}$. The values of $S_{1}$ were constant at $\sim 0.55 \%$ and the values of $S_{2}$ ranged from 0.2 to $0.55 \%$. During these measurements, $\mathrm{CCN}_{1}$ showed higher values than $\mathrm{CCN}_{2}$, which is in agreement with its larger $S$. The difference between $\mathrm{CCN}_{1}$ and $\mathrm{CCN}_{2}$ increased with decreasing $S_{2}$ (e.g., at time $\sim$ 19:45 UTC, when $\mathrm{CCN}_{2}$ values are around $300 \mathrm{~cm}^{-3}$ and $\mathrm{CCN}_{1}$ values are around $700 \mathrm{~cm}^{-3}$ ). The $\mathrm{mCCN}_{1}, \mathrm{mCCN}_{2}$, and $\mathrm{NCCN}_{2}$ for this group of measurements are shown in Fig. 9. The average measurements of $\mathrm{CCN}_{1}\left(\mathrm{TmCCN}_{1}\right)$ assumed to correct the $\mathrm{CCN}_{2}$ for aerosol load (FA) presented a standard deviation of $14 \%$, indicating a small impact on the parameterization proposed to fit the Twomey equation (Eq. 1). The power-fit equation from $\mathrm{NCCN}_{2}$ and $\mathrm{mS}_{2}$ measurements is shown. The values of $N_{0}$ and $k$ are $1015 \mathrm{~cm}^{-3}$ and 0.54 , respectively.

This procedure was applied to all cloud-profiling flights with measurements of $N_{\mathrm{CCN}}(S)$ with variable $S$ below cloud base. The $N_{0}$ and $k$ slope parameters for all groups of measurements during the campaign are shown in Fig. 10. The measurements show that in less polluted conditions, the values of $N_{0}(k$ slope $)$ are near $1000(0.5)$, while in more polluted conditions, values of $N_{0}$ ( $k$ slope) greater than 2000 (0.9) are observed. Additionally, the correlation coefficient values for almost all power-fit equations are around 0.9. The calculated $N_{\mathrm{CCN}}(S)$ errors for these flight segments are a function of the measured particle number, such that the error is $10 \%$ of $N_{\mathrm{CCN}}(S)$ for large concentrations and the mean of the error is around $20 \%$ of $N_{\mathrm{CCN}}(S)$. The estimated standard error (SE) for the $N_{0}$ and $k$ parameters and $\mathrm{CCN}$ estimates were calculated (as described in Appendix B) for each flight segment and are shown in Table 2. The table shows that the SE associated with the Twomey equation

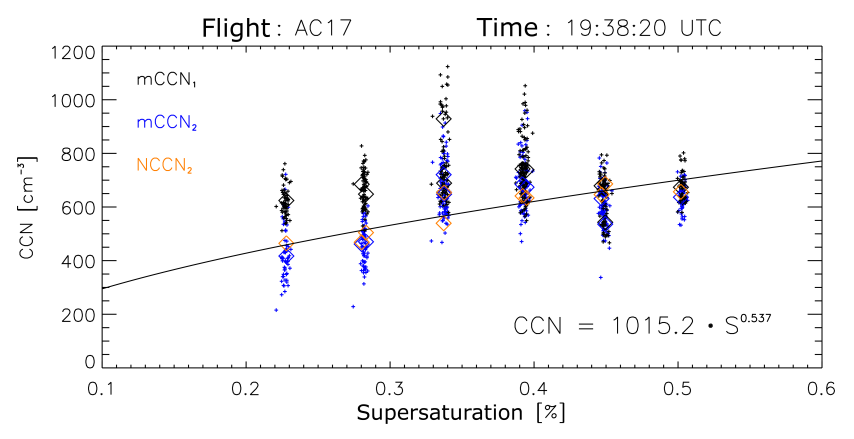

Figure 9. A comparison of the $\mathrm{CCN}$ spectra derived from the two $\mathrm{CCN}$ counter columns onboard the HALO aircraft during flight AC17. Black (blue) smaller dots indicate $\mathrm{CCN}_{1}\left(\mathrm{CCN}_{2}\right)$ measurements for each second. Large diamonds in black (blue) indicate the $\mathrm{mCCN}_{1}\left(\mathrm{mCCN}_{2}\right)$ for each time step of measurements. The orange large diamonds indicate the $\mathrm{NCCN}_{2}$ values that are used to fit the power-law equation for the group of measurements, which is shown in the lower right corner of the plot. The standard error for the CCN spectra derived is shown in Table 2.
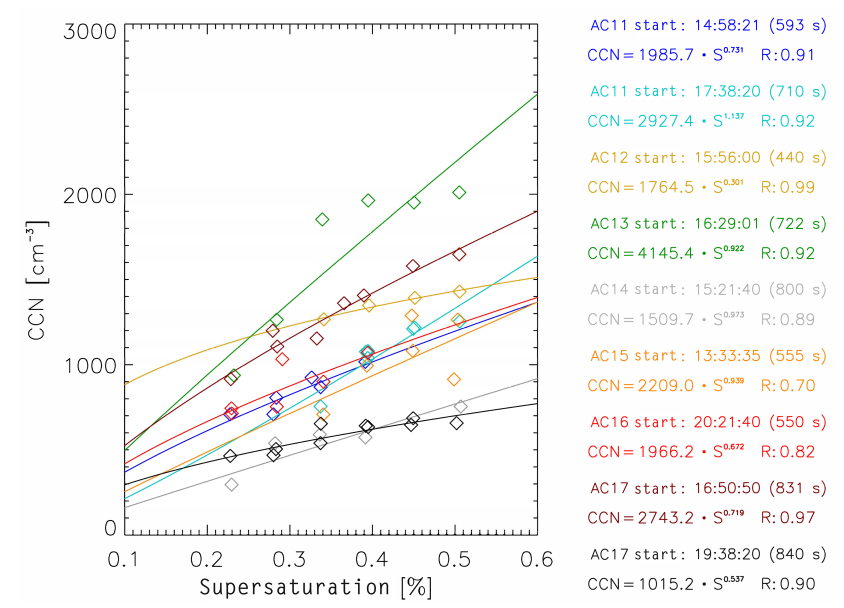

Figure 10. CCN spectra as measured onboard the HALO aircraft during cloud-profiling flights. The diamonds indicate the $\mathrm{NCCN}_{2}$ values, which are used to fit the power-law equation for the group of measurements. The colors indicate the group of measurements and match the legend on the right side of the plot. The legend indicates the flight number, the initial time of group measurements, the period of measurements in seconds, the power-law fit, and the correlation coefficient of the data. The standard errors for each CCN spectrum derived are shown in Table 2.

fit is about $5 \%$ for the $N_{0}$ and $k$ parameters. The changes in the air mass assumed to correct the $\mathrm{CCN}_{2}$ for FA during the flight segments were up to $24 \%$ for all flights. When the cloud segment compared with these data is not in exactly the same location at which the measurements were performed, the mean (i.e., $\mathrm{TmCCN}_{1}$ ) is a good measure for this comparison. The standard error was used for the error propagation calculations, and the resulting error in $N_{\mathrm{CCN}}(S)$ is $15 \%$ of the $N_{\mathrm{CCN}}(S)$ estimates on average. The resulting error in $N_{0}$ 
Table 2. Estimates of $N_{0}$ and $k$ below cloud base and their standard error (SE) for each case study. Maximum and minimum SE (SE CCNmax and SE CCNmin, respectively) for the CCN measurements are calculated considering errors in the supersaturation measurements $(\sim 10 \%)$. The details about the calculation of these values are given in Appendix B.

\begin{tabular}{cccccccc}
\hline Flight & Time & $N_{0}$ & $k$ & SE $N_{0}$ & SE $k$ & $\begin{array}{c}\text { SE } \\
\text { CCNmax } \\
{\left[\mathrm{cm}^{-3}\right]}\end{array}$ & $\begin{array}{c}\text { SE } \\
\text { CCNmin } \\
{\left[\mathrm{cm}^{-3}\right]}\end{array}$ \\
\hline AC11 & $14: 58: 21$ & 1985 & 0.73 & 81.6 & 0.035 & 25.5 & 24.8 \\
AC11 & $17: 38: 20$ & 2927 & 1.14 & 82.8 & 0.032 & 43.9 & 43.8 \\
AC12 & $15: 56: 00$ & 1764 & 0.3 & 71.4 & 0.046 & 19.0 & 22.7 \\
AC13 & $16: 29: 01$ & 4145 & 0.92 & 64.7 & 0.016 & 69.7 & 54.8 \\
AC14 & $15: 21: 40$ & 1509 & 0.97 & 44.8 & 0.028 & 24.7 & 18.9 \\
AC15 & $13: 33: 35$ & 2209 & 0.94 & 70.4 & 0.038 & 47.4 & 31.2 \\
AC16 & $20: 21: 40$ & 1966 & 0.67 & 69.5 & 0.029 & 26.5 & 21.2 \\
AC17 & $16: 50: 50$ & 2743 & 0.72 & 38.7 & 0.013 & 31.9 & 30.5 \\
AC17 & $19: 38: 20$ & 1015 & 0.54 & 18.5 & 0.018 & 10.7 & 9.4 \\
\hline
\end{tabular}

( $k$ slope) was also calculated and is $23 \%(20 \%)$ of the $N_{0}$ (k) values on average; this is associated with the Twomey equation fit and the $N_{\mathrm{CCN}}(S)$ error.

For some flights, the values estimated for the $N_{0}$ and $k$ parameters in Eq. (1) are similar those found by Pöhlker et al. (2016) for ground measurements at the Amazon Tall Tower Observatory (ATTO; $N_{0}=1469 \pm 78$ and $k=0.36 \pm 0.06$ ) during the dry season in the Amazon. However, in the majority of the cases $N_{0}$ and $k$ are 2 or 3 times greater than the values from Pöhlker et al. (2016). These differences are probably related to selectively flying to areas with high aerosol concentrations to contrast the cloud behavior with the flights with low aerosol concentrations, as shown in Fig. 2. The high CCN values measured in this study are more similar to previous aircraft measurements in smoky conditions over the Amazon (Andreae et al., 2004; Freud et al., 2008) than to the values observed at the ATTO.

\subsection{Comparing estimated with measured $N_{\mathrm{d}}$ near cloud base}

Cloud base drop concentrations obtained in several different ways were compared. Appendix $\mathrm{C}$ summarizes the measurements and theoretical calculations at cloud base. Agreement between these different estimates constitutes a closure. Section 5.2.1 discusses comparisons between individual cloud probe $N_{\mathrm{d}}$ measurements and the corresponding theoretical estimations of $N_{\mathrm{dT}}$ and $N_{\mathrm{dCCN}}$. Section 5.2.2 describes the comparisons between estimated $N_{\mathrm{d}}^{*}, N_{\mathrm{dT}}^{*}$, and $N_{\mathrm{dCCN}}^{*}$. Section 5.2.3 analyzes the agreement between $N_{\mathrm{d}}^{*}$ and $N_{\mathrm{a}}$.

\subsubsection{Comparison between $N_{\mathrm{d}}$ measurements with estimated $N_{\mathrm{dT}}$ and $N_{\mathrm{dCCN}}$}

The PMM procedure was applied to the measured $W_{\mathrm{b}}$ and $N_{\mathrm{d}}$ to analyze the spectrum of $N_{\mathrm{d}}, N_{\mathrm{dT}}$, and $N_{\mathrm{dCCN}}$ values near cloud base (as described in Sect. 4.2). This analytical method makes it possible to identify the role of $W_{\mathrm{b}}$ in pro-
Table 3. List of case studies for measurements below cloud base. The duration of measurements is given in seconds, starting at the initial time indicated. An asterisk indicates flights during which the two probes provided at least $20 \mathrm{~s}$ of measurements at cloud base. The data can be from different cloud passes in the same measurement region below cloud base.

\begin{tabular}{lccc}
\hline \multicolumn{4}{c}{ Measurements below cloud base } \\
\hline Flight & Date & $\begin{array}{c}\text { Initial } \\
\text { time } \\
\text { (UTC) }\end{array}$ & $\begin{array}{c}\text { Period of } \\
\text { analysis } \\
(\mathrm{s})\end{array}$ \\
\hline AC11 & 16 Sep 2014 & $14: 58: 21$ & 593 \\
AC11* & 16 Sep 2014 & $17: 38: 20$ & 710 \\
AC12 & 18 Sep 2014 & $15: 56: 00$ & 440 \\
AC13* & 19 Sep 2014 & $16: 29: 01$ & 722 \\
AC14* & 21 Sep 2014 & $15: 21: 40$ & 800 \\
AC15 & 23 Sep 2014 & $13: 33: 35$ & 555 \\
AC16* & 25 Sep 2014 & $20: 21: 40$ & 550 \\
AC17* & 27 Sep 2014 & $16: 50: 50$ & 831 \\
AC17* & 27 Sep 2014 & $19: 38: 20$ & 840 \\
\hline
\end{tabular}

ducing $N_{\mathrm{d}}$. Perfect agreement among the values is not expected due to the turbulent nature of the clouds, but the statistical modes of the measurements should have similar values to the theoretical estimation of the same modes of $N_{\mathrm{dCCN}}$ and $N_{\mathrm{dT}}$ within their uncertainty range. Figures 11 and 12 show $N_{\mathrm{dCCN}}, N_{\mathrm{dT}}$, and $N_{\mathrm{d}}$ values for the two cloud probes as a function of $W_{\mathrm{b}}$ for the cases presented in Table 3. The uncertainties regarding the $S_{\mathrm{max}}, N_{\mathrm{dCCN}}$, and $N_{\mathrm{dT}}$ estimates for measurements at cloud base with both probes (CCP-CDP and CAS-DPOL) are on average about 22, 20, and $38 \%$ for all flights, respectively (the uncertainty methods adopted for these theoretical estimates are available in Appendix A). The $W_{\mathrm{b}}$ uncertainty of $0.3 \mathrm{~m} \mathrm{~s}^{-1}$ accounts on average for about $65 \%(60 \%)$ of the $N_{\mathrm{dT}}\left(S_{\max }\right)$ uncertainty, and the uncer- 
(a)

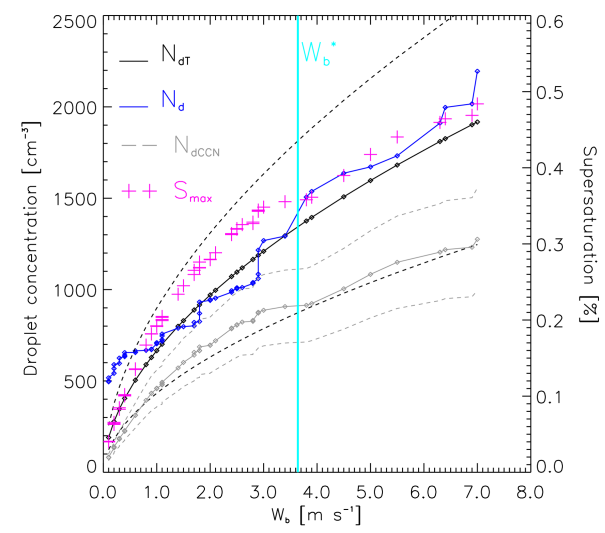

(c) FLIGHT AC14 TIME: 15:06 (184 s) $\mathrm{CCN}=1509.7 \cdot \mathrm{S}^{0.975}$

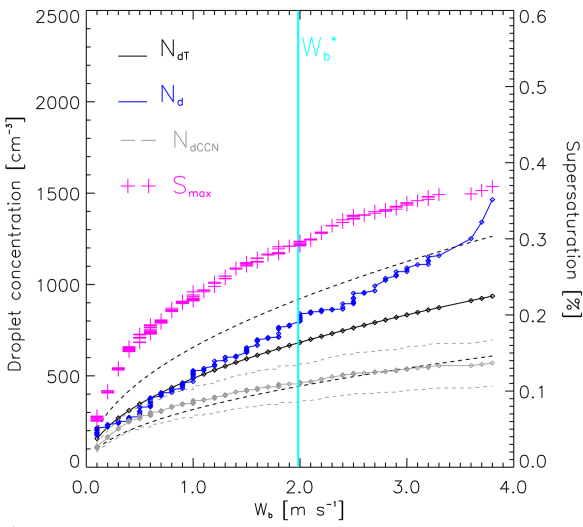

(e) FLIGHT AC17 TIME: $17: 06(58 \mathrm{~s}) \quad C C N=2743.2 \cdot \mathrm{S}^{0.719}$

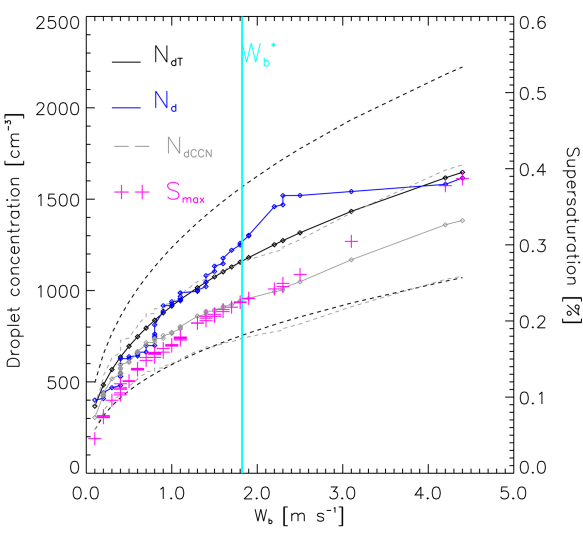

(b) FLIGHT AC13 TIME: 16:50 (72 s) $\quad$ CCN $=4145.4 \cdot \mathrm{S}^{0.022}$

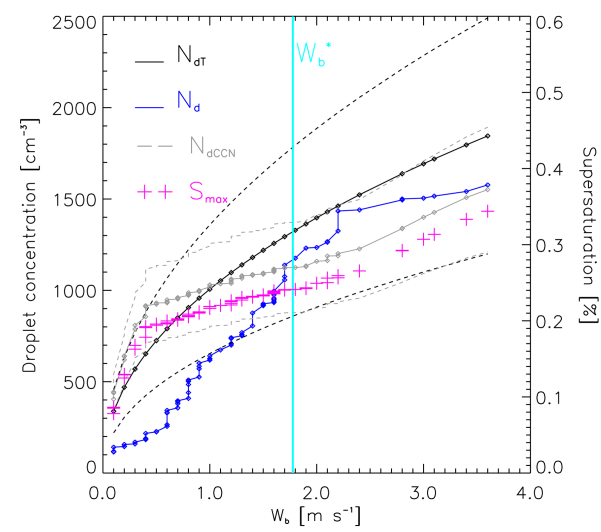

(d) FLIGHT AC16 TIME: 20:10 (58 s) $\quad$ CCN $=1966.2 \cdot \mathrm{s}^{0.672}$

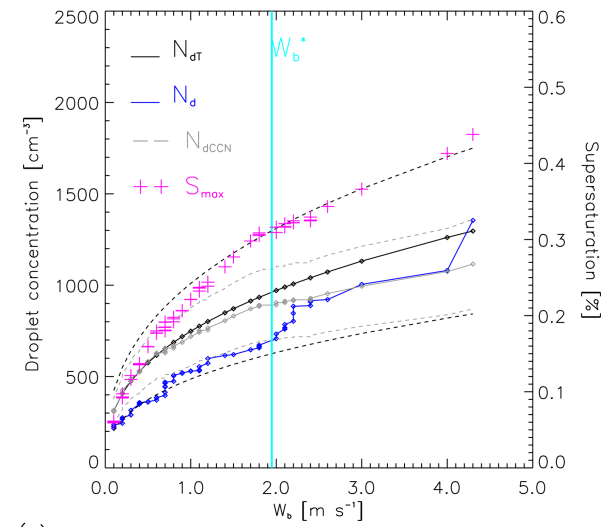

(f) FLIGHT AC17 TIME: $19: 16(31 \mathrm{~s}) \quad \mathrm{CCN}=1015.2 \cdot \mathrm{S}^{0.537}$

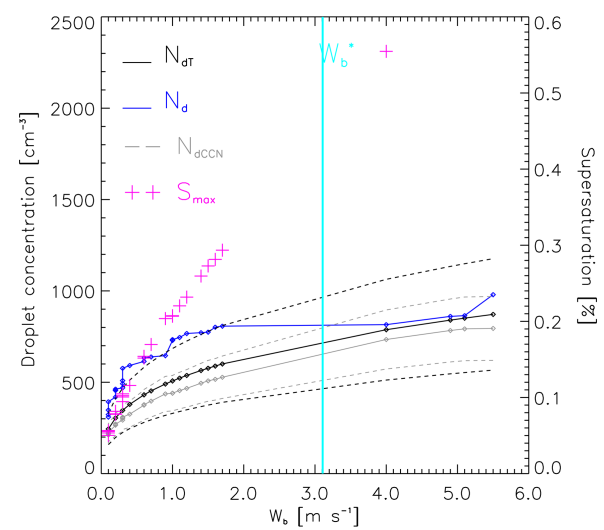

Figure 11. (a)-(f) $N_{\mathrm{dCCN}}, S, N_{\mathrm{dT}}$, and $N_{\mathrm{d}}$ values are presented as a function of the cloud base updrafts ( $W_{\mathrm{b}}$ ). This plot is based on the "probability matching method" (PMM) using the same percentiles for $W_{\mathrm{b}}$ and $N_{\mathrm{d}}\left(N_{\mathrm{dCCN}}\right.$ or $\left.N_{\mathrm{dT}}\right)$. The values of $N_{\mathrm{dCCN}}, N_{\mathrm{dT}}$, and $N_{\mathrm{d}}$ are shown on the left $y$ axis and those of $S$ are on the right $y$ axis. The black dashed lines are the $N_{\mathrm{dT}}$ uncertainties. The gray solid (dashed) lines are the $N_{\mathrm{dCCN}}$ values (uncertainties). The effective updraft $W_{\mathrm{b}}^{*}$ for each flight segment is shown by the cyan line. The data are based on the CAS-DPOL probe. The time period of measurements (sample size in seconds) and $N_{\mathrm{CCN}}(S)$ equation are shown on the top of the figures.

tainty from the estimated $S_{\max }$ contributes most of the $N_{\mathrm{dCCN}}$ uncertainty ( $\sim 70 \%$ on average).

The values of both Ncas and Ncdp are within the range of the theoretical expectation of $N_{\mathrm{dT}}$ and $N_{\mathrm{dCCN}}$, except for occasional deviations at the extreme percentiles. For example, the maximum $N_{\mathrm{dT}}$ vs. the maximum $N_{\mathrm{d}}$ is outside the error interval for $N_{\mathrm{dT}}$. This is because extreme percentiles are much more prone to random variations than the middle range, such as the median.

The curves for $N_{\mathrm{dT}}$ mostly agreed quite well with those for $N_{\mathrm{d}}$ with only small deviations. The $N_{\mathrm{dCCN}}$ mostly underestimates $N_{\mathrm{d}}$ by as much as a factor of 0.5 for reasons that we 
(a) FLIGHT AC11 TIME: $17: 52$ (61 s) $\quad \mathrm{CCN}=2927.4 \cdot \mathrm{S}^{1.137}$

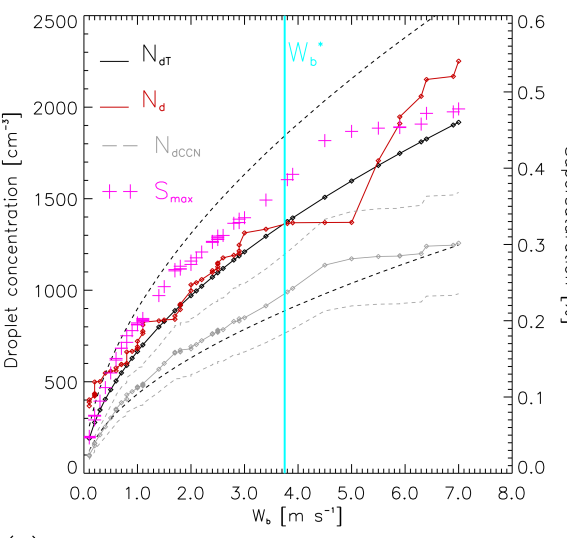

(c) FLIGHT AC17 TIME: $17: 06$ (74 s) $\quad$ CCN $=2743.2 \cdot \mathrm{S}^{0.719}$

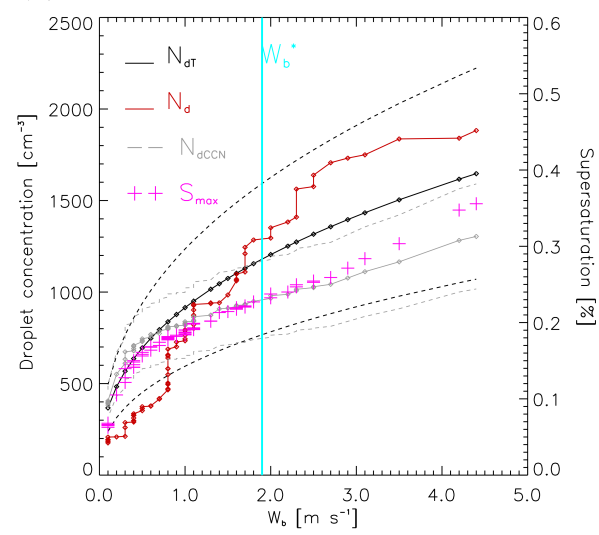

(b) FLIGHT AC14 TIME: $15: 06(111 \mathrm{~s}) \quad \mathrm{CCN}=1509.7 \cdot \mathrm{S}^{0.973}$

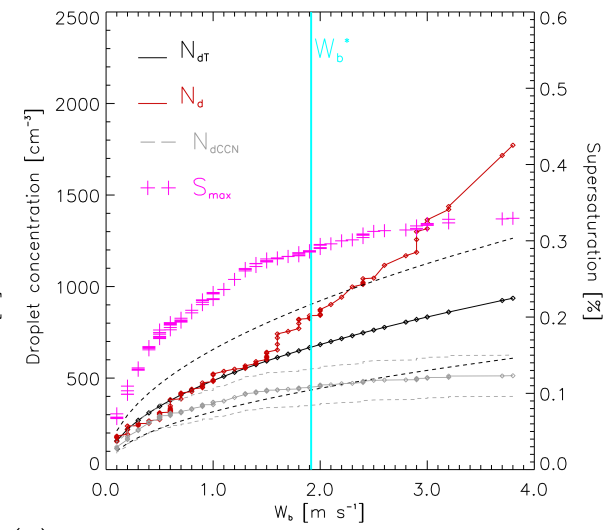

(d) FLIGHT AC17 TIME: 19:16 (48 s) CCN $=1015.2 \cdot \mathrm{S}^{0.537}$

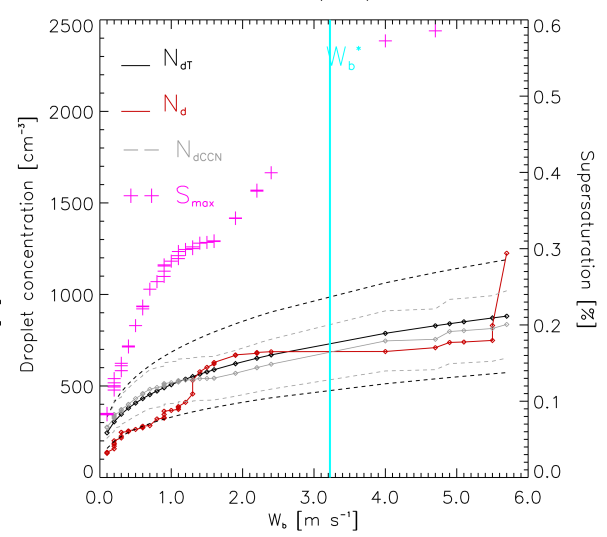

Figure 12. (a)-(d) The same as in Fig. 11 for the CCP-CDP probe. No data were available for flight AC16. The CCP-CDP malfunctioned in flight $\mathrm{AC} 13$ during the cloud base measurements.

could not identify. Entrainment is not likely because it would dilute $N_{\mathrm{d}}$ and thus cause $N_{\mathrm{dCCN}}$ to be biased positively with respect to $N_{\mathrm{d}}$. It appears that measuring $S$ in clouds is still a great challenge, even indirectly by using Eq. (3). Remarkably, Eq. (2) (Twomey, 1959), which avoids an explicit usage of $S$, still performs better when limited within the observed bounds of $W_{\mathrm{b}}$ and $S$ within the cloud. These results support the analyses concerning the $N_{\mathrm{d}}$ measurement at cloud base that are presented in the next sections.

\subsubsection{Comparing estimated $N_{\mathrm{d}}^{*}$ with $N_{\mathrm{dT}}^{*}$ and $N_{\mathrm{dCCN}}^{*}$}

Assuming that $W_{\mathrm{b}} *$ represents the updraft velocity for a set of cloud base measurements, the corresponding measured $N_{\mathrm{d}}^{*}$ from CAS-DPOL and CCP-CDP should ideally have similar values to the estimated $N_{\mathrm{dCCN}}^{*}$ and $N_{\mathrm{dT}}^{*}$. The uncertainties in $N_{\mathrm{dCCN}}^{*}$ and $N_{\mathrm{dT}}^{*}$ are $\sim 20$ and $\sim 35 \%$ on average, respectively. Figure 13a shows the values of $N_{\mathrm{d}}^{*}$ and $N_{\mathrm{dT}}^{*}$ for the different cloud base measurements shown in Figs. 11 and 12. The $N_{\mathrm{dT}}^{*}$ agrees with $N_{\mathrm{d}}^{*}$ within the measurement uncertainties, as shown by the error bars. The bias of $N_{\mathrm{dT}}^{*}$ with respect to $N_{\mathrm{d}}^{*}$ for the CAS-DPOL is 1.00 with a standard deviation of \pm 0.17 . The respective result for the CDP is
$0.84 \pm 0.12$. Weaker agreement is observed for comparisons between $N_{\mathrm{dCCN}}^{*}$ and $N_{\mathrm{d}}^{*}$ (see Fig. 13b). A factor of $\sim 2$ can be observed for some cases (AC14 and AC17). The bias of $N_{\mathrm{dCCN}}^{*}$ with respect to $N_{\mathrm{d}}^{*}$ for the CAS-DPOL is $0.80 \pm 0.07$. The respective result for the CDP is $0.76 \pm 0.1$.

\subsubsection{Comparing estimated $N_{\mathrm{d}}^{*}$ with $N_{\mathrm{a}}$}

Another possibility for cloud base closure is via a comparison of $N_{\mathrm{d}}^{*}$ and $N_{\mathrm{a}}$ estimates from measurements of the vertical evolution of $r_{\mathrm{e}}$ in pristine and polluted conditions. In these situations, the estimated values for these parameters are expected to converge. Figure 14a shows the calculated $N_{\mathrm{a}}$ with CCP-CDP probe results from cloud measurements during flight AC17. The estimated $N_{\mathrm{a}}$ in this case is $1496 \mathrm{~cm}^{-3}$; considering evaporation losses due to cloud mixing, the expected number of droplets at cloud base is $1047 \mathrm{~cm}^{-3}$ after applying the correction by a reduction of $30 \%$ (Freud et al., 2011), which is a factor of 0.7. The $N_{\mathrm{d}}^{*}$ for the same flight segment is $1207 \mathrm{~cm}^{-3}$, as calculated from CCP-CDP data (see Fig. 7b). The factor of 0.7 applied to the estimates of $N_{\mathrm{a}}$ corroborates the methodology of Freud et al. (2011) for retrieving the effective number of droplets nucleated at cloud 

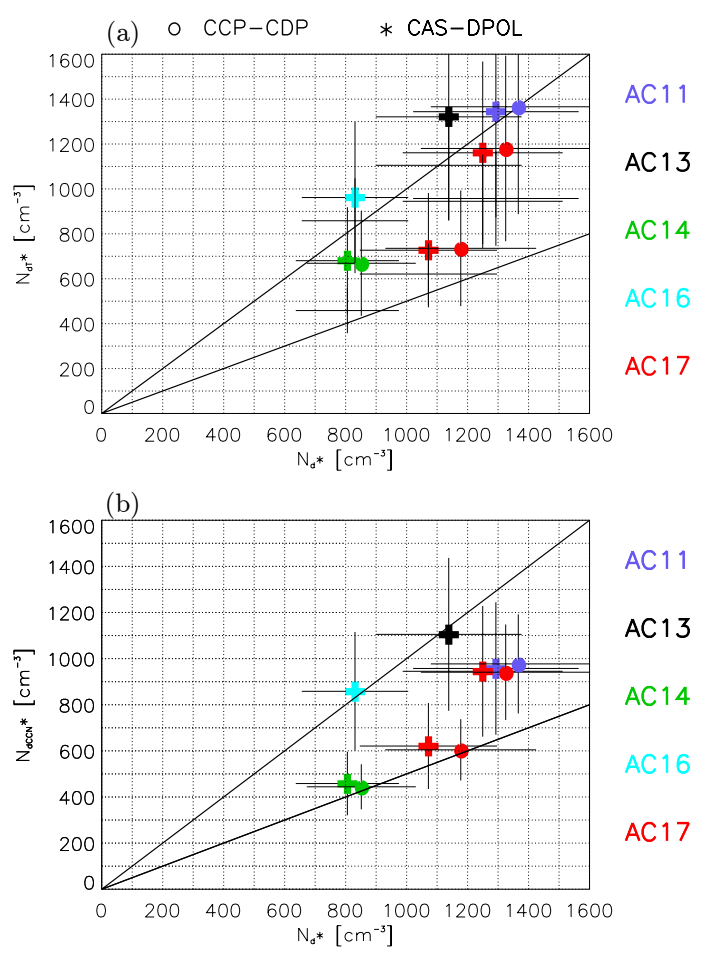

Figure 13. (a) $N_{\mathrm{d}}^{*}$ vs. $N_{\mathrm{dT}}^{*}$ calculated with $W_{\mathrm{b}}^{*}$ from the cloud base data shown in Figs. 11 and 12. The CAS-DPOL values are indicated by plus symbols $(+)$ and the CCP-CDP values are indicated by circles (o). The colors indicate each flight segment (legend on the right side of the plot). The error bars indicate the uncertainties in variable estimates. The lines show the $1: 1$ and $1: 2$ relationships between $N_{\mathrm{dT}}^{*}$ vs. $N_{\mathrm{d}}^{*}$ for each probe. (b) The same for $N_{\mathrm{d}}^{*}$ vs. $N_{\mathrm{dCCN}}^{*}$.

base, even though a different dataset was used here. A close relationship between $M_{\mathrm{v}}$ and $r_{\mathrm{e}}$ as a function of height is shown in Fig. 14b. Similar results were found for cloud profile measurements during the other flights.

The values of $N_{\mathrm{a}}$ and $N_{\mathrm{d}}^{*}$ were calculated for all profile flights and cloud probes, and the results are shown in Fig. 15. The uncertainties in $N_{\mathrm{a}}\left(N_{\mathrm{d}}^{*}\right)$ estimates from CAS-DPOL and CCP-CDP are $\sim 25 \%(21 \%)$ and $\sim 14 \%(10 \%)$, respectively. The comparisons between the estimated $N_{\mathrm{a}}$ and $N_{\mathrm{d}}^{*}$ show a linear correlation with correlation coefficients greater than 0.97 for all cloud probes. The linear regression between $N_{\mathrm{d}}^{*}$ and $N_{\mathrm{a}}$ estimates shows a slope close to 1 for CAS-DPOL and CCP-CDP. More specifically, the bias of $N_{\mathrm{a}}$ with respect to $N_{\mathrm{d}}^{*}$ for the CAS-DPOL is $1.12 \pm 0.19$. The respective result for the CDP is $0.7 \pm 0.19$.

The lower slope for the CDP (Fig. 15b) compared to the CAS-DPOL (Fig. 15a) can be explained by the relative overestimate of $r_{\mathrm{e}}$ of the CDP compared to the CAS-DPOL, which translates to an underestimate of $N_{\mathrm{a}}$. This is inferred from Fig. 4, which shows that the CDP has about $20 \%$ more CWC compared to the CAS-DPOL and the hot-wire CWC.

These results show good agreement with the theoretical expectations, especially based on the CAS-DPOL. The
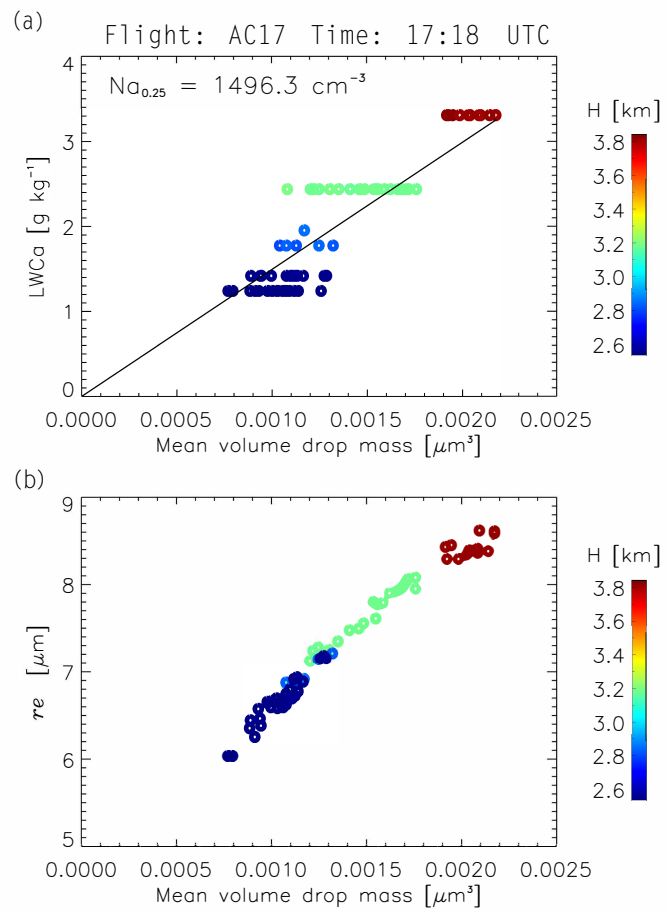

Figure 14. (a) Mean volume drop mass $\left(M_{\mathrm{V}}\right)$ vs. liquid water content from the CCP-CDP measurements for adiabatic fractions greater than $0.25\left(\mathrm{LWC}_{\mathrm{a}}\right)$. Values are shown with different colors labeled as a function of height in kma.s.l. (kilometers above sea level; indicated by the color bar on the right side of the figure). The slope of the linear equation is the estimated $N_{\mathrm{a}}$ (i.e., $1496 \mathrm{~cm}^{-3}$ ). (b) $M_{\mathrm{V}}$ vs. $r_{\mathrm{e}}$ as a function of height in $\mathrm{km}$ a.s.l. (indicated by the color bar on the right side of the figure).

flights performed in near-pristine and polluted conditions can be distinguished based on the CAS-DPOL estimates of $N_{d}^{*}$ and $N_{\mathrm{a}}$ values. For example, flight AC19 was performed over the Atlantic Ocean in clean conditions. The CAS-DPOL estimated values of $N_{\mathrm{d}}^{*}$ and $N_{\mathrm{a}}$ are $\sim 270 \mathrm{~cm}^{-3}$, whereas for flights $\mathrm{AC} 07$ and $\mathrm{AC} 11$ performed under polluted conditions, the values of $N_{\mathrm{d}}^{*}$ and $N_{\mathrm{a}}$ are greater than $1000 \mathrm{~cm}^{-3}$.

In general, the similarities of $N_{\mathrm{a}}$ and $N_{\mathrm{d}}^{*}$ values (see Fig. 15) support the methodology of calculating the effective number of droplets observed at convective cloud base from the vertical profile of measured $r_{\mathrm{e}}$ or $M_{\mathrm{v}}$. Some qualification might exist for the most polluted flights, e.g., AC08, in which $N_{\mathrm{a}}$ is larger than $N_{\mathrm{d}}^{*}$ by a factor of $\sim 20-30 \%$. The vertical profiles of the $N_{\mathrm{d}}$ measurements indicate that in these cases the $N_{\mathrm{d}}$ measurements up to $2-3 \mathrm{~km}$ above cloud base were larger than those at cloud base. A higher aerosol concentration at these greater heights was also observed in aerosol probe measurements (not shown), suggesting that secondary droplet nucleation was taking place on the most polluted flights. The $N_{\mathrm{a}}$ calculation does not take into account the possibility of new nucleation above cloud base (Freud et al., 2011). Therefore, the assumed adiabatic growth of droplets 

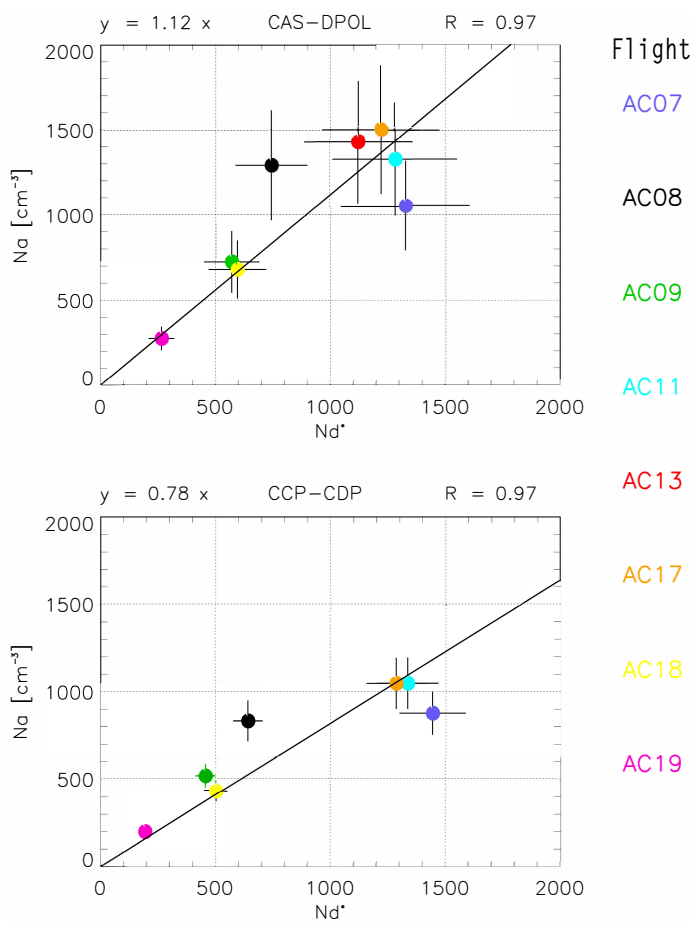

Figure 15. $N_{\mathrm{d}}^{*}$ vs. $N_{\mathrm{a}}$ measured with CAS-DPOL and CCP-CDP (indicated on the top of the panels) for profile flights during the ACRIDICON-CHUVA campaign. The color of the dots is associated with the flight number shown at the right side of the panels. The error bars indicate the uncertainties in variable estimates. The linear regression equation and the correlation coefficient $R$ are shown at the top of each panel.

via condensation from cloud base to higher levels within the cloud can lead to an overestimation of the number of droplets at cloud base by $\sim 20-30 \%$ when $N_{\mathrm{a}}$ is calculated in cases with secondary droplet nucleation.

\section{Summary and conclusions}

This study is focused on testing parameterizations used for the recently developed methodology for satellite retrievals of $N_{\mathrm{a}}, W_{\mathrm{b}}^{*}$, and CCN in convective clouds based on aircraft measurements during the ACRIDICON-CHUVA campaign in the Amazon. It is the first time that these new parameterizations have been comprehensively tested alongside old parameterizations. Liquid water content measurements from a hot-wire device were taken as a reference for the quality assessment of estimated CWC from cloud probe DSDs near cloud base. The intercomparison of the DSDs and the CWC derived from the different instruments generally shows good agreement within the instrumental uncertainties. The values of $N_{\mathrm{d}}$ near cloud base were comparable within the measurement errors with their inferred values based on the measured $W_{\mathrm{b}}^{*}$ and $N_{\mathrm{CCN}}(S)$. The values of $W_{\mathrm{b}}^{*}$ were calculated from the measured spectrum of $W_{\mathrm{b}}$ using the parameterization of
Rosenfeld et al. (2014a), which is also used to retrieve cloud base updraft from satellites (Zheng et al., 2015). In addition, $N_{\mathrm{d}}$ near cloud base compared well with $N_{\mathrm{a}}$ (within $\pm 20 \%$ ) obtained from the vertical evolution of cloud drop effective radius $\left(r_{\mathrm{e}}\right)$ above cloud base. The values of $N_{\mathrm{a}}$ in this study were obtained with the same parameterization that has been recently developed for satellite-calculated $N_{\mathrm{a}}$ based on the satellite-retrieved vertical evolution of $r_{\mathrm{e}}$ in convective clouds (Freud et al., 2011; Rosenfeld et al., 2014a). These results support the methodology of deriving $N_{\mathrm{a}}$ based on the rate of $r_{\mathrm{e}}$ growth with cloud depth and under the assumption that the entrainment and mixing of air into convective clouds is extremely inhomogeneous.

The measured effective droplet numbers $\left(N_{\mathrm{d}}^{*}\right)$ at cloud base were also compared against $N_{\mathrm{dT}}^{*}$, which is its predicted value based on the old parameterization in Eq. (2) (Twomey, $1959)$ that uses $W_{\mathrm{b}}^{*}$ and the $N_{\mathrm{CCN}}(S)$ power law. A newer parameterization calculates $N_{\mathrm{dCCN}}^{*}$ by substituting $S$ into the power law $N_{\mathrm{CCN}}(S)$, where $S$ is obtained from Eq. (3) (Pinsky et al., 2012). The agreement between $N_{\mathrm{d}}^{*}$ and $N_{\mathrm{dCCN}}^{*}$ was only within a factor of 2 , underlining the yet unresolved challenge of aircraft measurements of $S$ in clouds.

In summary, the measurements of $N_{\mathrm{CCN}}(S)$ and $W_{\mathrm{b}}$ reproduced the observed $N_{\mathrm{d}}$ with Twomey's parameterization, but using $S$ measured in clouds remains a challenge. Furthermore, the vertical evolution of $r_{\mathrm{e}}$ with height reproduced the observation-based adiabatic cloud base drop concentrations, $N_{\mathrm{a}}$. The combination of these results provides aircraft observational support for the various components of the satellite retrieval methodology that was recently developed to retrieve $N_{\mathrm{CCN}}(S)$ below the base of convective clouds (Rosenfeld et al., 2016).

Data availability. Data are available at https://halo-db.pa.op.dlr. de/. 


\section{Appendix A: Calculation of measurement uncertainties}

The uncertainties in $N_{\mathrm{dT}}, N_{\mathrm{dCCN}}, S_{\mathrm{max}}, r_{\mathrm{e}}, \mathrm{CWC}, N_{\mathrm{a}}$, $N_{\mathrm{d}}^{*}, N_{\mathrm{dT}}^{*}$, and $N_{\mathrm{dCCN}}^{*}$ were estimated via the "analytic" approximation of error propagation, which is calculated by finding the partial derivatives of the function with respect to the independent variables. For example, for a function $f(x$, $y, z$ ) with the variables $x, y$, and $z$ and the uncertainties $s_{x}$, $s_{y}$, and $s_{z}$, the following result is for the final uncertainty $\left(s_{\mathrm{f}}\right)$ of $f$ :

$s_{\mathrm{f}}=\sqrt{\left(\frac{\delta f}{\delta x}\right)^{2} \cdot s_{x}^{2}+\left(\frac{\delta f}{\delta y}\right)^{2} \cdot s_{y}^{2}+\left(\frac{\delta f}{\delta z}\right)^{2} \cdot s_{z}^{2}}$.

\section{Appendix B: Calculation of standard error for CCN measurements}

\section{B1 Calculating SE CCNmax and SE CCNmin}

The $N_{0}$ and $k$ parameter standard errors (SEs) are associated with the statistical uncertainty of the power-law-function fit. To compute the SE for the CCN estimates, the uncertainties in $S(\sim 10 \%)$ are considered. Then, the maximum and the minimum SE values expected for the $\mathrm{CCN}$ estimates are calculated as follows:

Maximum DE

$\operatorname{SE~CCNmax~}=\frac{\left[\left(N_{0}+\mathrm{SD} \cdot N_{0}\right) \cdot\left(S_{i} \cdot 1.1\right)^{k+\mathrm{SD} \cdot k}\right]-N_{0} \cdot S_{i}^{k}}{\sqrt{N}}$,

where the averaging is done on $I=1: N$ and $N$ is the number of $\mathrm{NCCN}_{2}$ cases for each group of measurements. SD $\cdot N_{0}$ is the statistical standard deviation of $N_{0}$ and $\mathrm{SD} \cdot k$ is the statistical standard deviation of $k . S_{i}$ is the supersaturation in each step, forced to have the maximum value (multiplied by 1.1 ): Minimum SE

$\mathrm{SE} \mathrm{CCNmin}=\frac{N_{0} \cdot S_{i}^{k}-\left[\left(N_{0}-\mathrm{SD} \cdot N_{0}\right) \cdot\left(S_{i} \cdot 0.9\right)^{k-\mathrm{SD} \cdot k}\right]}{\sqrt{N}}$,

where the averaging is done on $I=1: N$ and $N$ is the number of $\mathrm{NCCN}_{2}$ cases for each group of measurements. SD $\cdot N_{0}$ is the statistical standard deviation of $N_{0}$ and SD $\cdot k$ is the statistical standard deviation of $k . S_{i}$ is the supersaturation in each step, forced to have the minimum value (multiplied by 0.9 ).

\section{B2 Error and uncertainties in Twomey's formula (Eq. 1)}

According to Krüger et al. (2014), the error in $N_{\mathrm{CCN}}(S)$ based on the counting error in the measured particle number $(\Delta c=\sqrt{c+1})$ can be calculated by

$\Delta N=\sqrt{\left(\frac{\Delta c \cdot t}{q}\right)^{2}+\left(\frac{c \cdot \Delta q \cdot t}{q^{2}}\right)^{2}+\left(\frac{c \cdot \Delta t}{q}\right)^{2}}$,

where $t$ is the period of the time of measurements assumed $(60 \mathrm{~s}), \Delta t$ is the error in the time, $c$ is the measured particle number, $q$ is the aerosol flow rate, and $\Delta q$ is the error in the aerosol flow rate (we assume $10 \%$ of $q$; i.e., $0.007 \mathrm{~L} \mathrm{~min}^{-1}$ ).

According to the Gaussian error propagation, the error in $N_{\mathrm{CCN}}(S)$ is

\section{$\triangle \mathrm{NCCN}=$}

$$
\sqrt{\left(\frac{\Delta \mathrm{mCCN} 2 \cdot \mathrm{TmCCN} 1}{\mathrm{mCCN} 1}\right)^{2}+\left(-\frac{\mathrm{mCCN} 2 \cdot \Delta \mathrm{mCCN} 1}{\mathrm{mCCN} 1^{2}}\right)^{2}}
$$

To calculate the error in $k$ the calculations have been done with the upper and lower error ranges and the resulting error in $k$ is $20 \%$ of $k$. For $N_{0}$ the calculated error is $23 \%$, associated with the Twomey equation fit (Eq. 1) and the $N_{\mathrm{CCN}}$ error.

\section{Appendix C: Cloud base calculations}

Summary of the measurements and theoretical calculations at cloud base:

$\begin{array}{ll}N_{\mathrm{d}} & \text { based on probe measurement } \\ N_{\mathrm{a}} & \text { based on vertical profile of } r_{\mathrm{e}} \\ S_{\mathrm{max}} & S \text { substituting } N_{\mathrm{d}} \text { and } W_{\mathrm{b}} \text { in Eq. (3) } \\ N_{\mathrm{dT}} & \text { Obtained by substituting in Eq. (2) } \\ & W_{\mathrm{b}} \text { and } N_{\mathrm{CCN}}(S) \text { parameters }(k \text { and } \\ & \left.N_{0}\right) \\ N_{\mathrm{dCCN}} & \text { Obtained by substituting } S_{\mathrm{max}} \text { and } \\ & N_{\mathrm{CCN}}(S) \text { parameters in Eq. }(1) \\ W_{\mathrm{b}}^{*} & \text { Obtained from Eq. }(6) \\ N_{\mathrm{d}}^{*}, N_{\mathrm{dT}}^{*}, N_{\mathrm{dCCN}}^{*} & N_{\mathrm{d}}, N_{\mathrm{dT}}, N_{\mathrm{dCCN}} \text { that match } W_{\mathrm{b}}^{*}\end{array}$


Competing interests. The authors declare that they have no conflict of interest.

Acknowledgements. The first two authors of this study were supported by project BACCHUS, European Commission FP7-603445. The generous support of the ACRIDICON-CHUVA campaign by the Max Planck Society, the German Aerospace Center (DLR), FAPESP (São Paulo Research Foundation), and the German Science Foundation (Deutsche Forschungsgemeinschaft; DFG) within the DFG priority program (SPP 1294) "Atmospheric and Earth System Research with the Research Aircraft HALO (High Altitude and Long Range Research Aircraft)" is greatly appreciated. This study was also supported by the EU Project HAIC under FP7AAT-2012-3.5.1-1 and by the German Science Foundation within DFG SPP 1294 HALO by contract no. VO1504/4-1 and contract no. JU 3059/1-1. Christoph Mahnke and Ralf Weigel received funding from the German Federal Ministry of Education and Research (BMBF; Bundesministerium für Bildung und Forschung) within the joint ROMIC-SPITFIRE project (01LG1205A). The first author also acknowledges financial support from the Brazilian funding agencies CAPES and CNPq during his PhD studies.

Edited by: Ulrich Schumann

Reviewed by: four anonymous referees

\section{References}

Andreae, M. O.: Correlation between cloud condensation nuclei concentration and aerosol optical thickness in remote and polluted regions, Atmos. Chem. Phys., 9, 543-556, https://doi.org/10.5194/acp-9-543-2009, 2009.

Andreae, M. O., Rosenfeld, D., Artaxo, P., Costa, A. A., Frank, G. P., Longo, K. M., and Silva-Dias, M. A. F.: Smoking rain clouds over the Amazon, Science, 303, 1337-1342, https://doi.org/10.1126/science.1092779, 2004.

Artaxo, P., Martins, J. V., Yamasoe, M. A., Procópio, A. S., Pauliquevis, T. M., Andreae, M. O., Guyon, P., Gatti, L. V., and Leal, A. M. C.: Physical and chemical properties of aerosols in the wet and dry seasons in Rondônia, Amazonia, J. Geophys. Res.-Atmos., 107, 1-14, https://doi.org/10.1029/2001JD000666, 2002.

Baumgardner, D., Strapp, W., and Dye, J. E.: Evaluation of the forward scattering spectrometer probe. Part II: corrections for coincidence and dead-time losses, J. Atmos. Ocean. Tech., 2, 626-632, https://doi.org/10.1175/15200426(1985)002<0626:EOTFSS>2.0.CO;2, 1985.

Baumgardner, D., Jonsson, H., Dawson, W., O'Connor, D., and Newton, R.: The cloud, aerosol and precipitation spectrometer: a new instrument for cloud investigations, Atmos. Res., 59-60, 251-264, https://doi.org/10.1016/S0169-8095(01)001193, 2001.

Baumgardner, D., Chepfer, H., Raga, G. B., and Kok, G. L.: The shapes of very small cirrus particles derived from in situ measurements, Geophys. Res. Lett., 32, 1-4, https://doi.org/10.1029/2004GL021300, 2005.

Beals, M. J., Fugal, J. P., Shaw, R. A., Lu, J., Spuler, S. M., and Stith, J. L.: Holographic measurements of inhomogeneous cloud mixing at the centimeter scale, Science, 350, 87-90, https://doi.org/10.1126/science.aab0751, 2015.

Brenguier, J. L., Bachalo, W. D., Chuang, P. Y., Esposito, B. M., Fugal, J., Garrett, T., Gayet, J. F., Gerber, H., Heymsfield, A., Kokhanovsky, A., Korolev, A., Lawson, R. P., Rogers, D. C., Shaw, R. A., Strapp, W., and Wendisch, M.: In situ measurements of cloud and precipitation particles in airborne measurements for environmental research: methods and instruments, Science, 303, 1337-1342, https://doi.org/10.1126/science.1092779, 2013.

Burnet, F. and Brenguier, J. L.: Observational study of the entrainment-mixing process in warm convective clouds, J. Atmos. Sci., 64, 1995-2011, https://doi.org/10.1175/JAS3928.1, 2007.

Dye, J. E. and Baumgardner, D.: Evaluation of the forward scattering spectrometer probe. Part I: electronic and optical studies, J. Atmos. Ocean. Tech., 1, 329-344, https://doi.org/10.1175/15200426(1984)001<0329:EOTFSS>2.0.CO;2, 1984.

Fan, J., Leung, L. R., DeMott, P. J., Comstock, J. M., Singh, B., Rosenfeld, D., Tomlinson, J. M., White, A., Prather, K. A., Minnis, P., Ayers, J. K., and Min, Q.: Aerosol impacts on California winter clouds and precipitation during CalWater 2011: local pollution versus long-range transported dust, Atmos. Chem. Phys., 14, 81-101, https://doi.org/10.5194/acp-14-81-2014, 2014.

Freud, E. and Rosenfeld, D.: Linear relation between convective cloud drop number concentration and depth for rain initiation, J. Geophys. Res.-Atmos., 117, 1-13, https://doi.org/10.1029/2011JD016457, 2012.

Freud, E., Rosenfeld, D., Andreae, M. O., Costa, A. A., and Artaxo, P.: Robust relations between $\mathrm{CCN}$ and the vertical evolution of cloud drop size distribution in deep convective clouds, Atmos. Chem. Phys., 8, 1661-1675, https://doi.org/10.5194/acp-8-16612008, 2008.

Freud, E., Rosenfeld, D. and Kulkarni, J. R.: Resolving both entrainment-mixing and number of activated $\mathrm{CCN}$ in deep convective clouds, Atmos. Chem. Phys., 11, 12887-12900, https://doi.org/10.5194/acp-11-12887-2011, 2011.

Frey, W., Borrmann, S., Kunkel, D., Weigel, R., De Reus, M., Schlager, H., Roiger, A., Voigt, C., Hoor, P., Curtius, J., Krämer, M., Schiller, C., Volk, C. M., Homan, C. D., Fierli, F., Di Donfrancesco, G., Ulanovsky, A., Ravegnani, F., Sitnikov, N. M., Viciani, S., D’Amato, F., Shur, G. N., Belyaev, G. V., Law, K. S., and Cairo, F.: In situ measurements of tropical cloud properties in the West African Monsoon: upper tropospheric ice clouds, mesoscale convective system outflow, and subvisual cirrus, Atmos. Chem. Phys., 11, 5569-5590, https://doi.org/10.5194/acp11-5569-2011, 2011.

Gayet, J.-F., Shcherbakov, V., Voigt, C., Schumann, U., Schäuble, D., Jeßberger, P., Petzold, A., Minikin, A., Schlager, H., Dubovik, O., and Lapyonok, T.: The evolution of microphysical and optical properties of an A380 contrail in the vortex phase, Atmos. Chem. Phys., 12, 6629-6643, https://doi.org/10.5194/acp12-6629-2012, 2012.

Haddad, Z. S. and Rosenfeld, D.: Optimality of Empirical Z-R Relations, Q. J. Roy. Meteorol. Soc., 123, 1283-1293, 1997.

Järvinen, E., Schnaiter, M., Mioche, G., Jourdan, O., Shcherbakov, V., Costa, A., Afchine, A., Krämer, M., Heidelberg, F., Jurkat, T., Voigt, C., Schlager, H., Nichman, L., Gallagher, M., Hirst, E., Schmitt, C., Bansemer, A., Heymsfield, A., Lawson, P., U.Tricoli, Pfeilsticker, K., Vochezer, P., Möhler, O., and Leis- 
ner, T.: Quasi-spherical ice in convective clouds, J. Atmos. Sci., https://doi.org/10.1175/JAS-D-15-0365.1, in press, 2016.

Jeßberger, P., Voigt, C., Schumann, U., Sölch, I., Schlager, H., Kaufmann, S., Petzold, A., Schäuble, D., and Gayet, J. F.: Aircraft type influence on contrail properties, Atmos. Chem. Phys., 13, 11965-11984, https://doi.org/10.5194/acp-13-119652013, 2013.

Jiang, H. and Feingold, G.: Effect of aerosol on warm convective clouds: aerosol-cloud-surface flux feedbacks in a new coupled large eddy model, J. Geophys. Res., 111, D01202, https://doi.org/10.1029/2005JD006138, 2006.

King, W. D., Parkin, D. A., and Handsworth, R. J.: A hot-wire liquid water device having fully calculable response characteristics, J. Appl. Meteorol., 17, 1809-1813, https://doi.org/10.1175/15200450(1978)017<1809:AHWLWD>2.0.CO;2, 1978.

Klingebiel, M., De Lozar, A., Molleker, S., Weigel, R., Roth, A., Schmidt, L., Meyer, J., Ehrlich, A., Neuber, R., Wendisch, M., and Borrmann, S.: Arctic low-level boundary layer clouds: In situ measurements and simulations of mono- and bimodal supercooled droplet size distributions at the top layer of liquid phase clouds, Atmos. Chem. Phys., 15, 617-631, https://doi.org/10.5194/acp-15-617-2015, 2015.

Knippertz, P., Coe, H., Chiu, C., Evans, M. J., Fink, A. H., Kalthoff, N., Liousse, C., Mari, C., Allan, R., Brooks, B., Danour, S., Flamant, C., Jegede, O. O., Lohou, F., and Marsham, J. H.: The DACCIWA project: Dynamics-aerosol-chemistry-cloud interactions in West Africa, B. Am. Meteorol. Soc., 96, 1451-1460, 2015.

Kohler, M.: Explicit prediction of ice clouds in general circulation models, in: ProQuest Dissertations And Theses, PhD Thesis, University of California, Los Angeles, p. 6157, 1999.

Korolev, A. V., Makarov, Y. E., and Novikov, V. S.: On the calibration of cloud particle counter FSSP-, Trans. Cent. Aerol. Obs., 158, 43-49, 1985.

Krüger, M. L., Mertes, S., Klimach, T., Cheng, Y. F., Su, H., Schneider, J., Andreae, M. O., Pöschl, U., and Rose, D.: Assessment of cloud supersaturation by size-resolved aerosol particle and cloud condensation nuclei (CCN) measurements, Atmos. Meas. Tech., 7, 2615-2629, https://doi.org/10.5194/amt-7-2615-2014, 2014.

Kuhn, U., Ganzeveld, L., Thielmann, A., Dindorf, T., Schebeske, G., Welling, M., Sciare, J., Roberts, G., Meixner, F. X., Kesselmeier, J., Lelieveld, J., Kolle, O., Ciccioli, P., Lloyd, J., Trentmann, J., Artaxo, P., and Andreae, M. O.: Impact of Manaus city on the Amazon Green Ocean atmosphere: ozone production, precursor sensitivity and aerosol load, Atmos. Chem. Phys., 10, 9251-9282, https://doi.org/10.5194/acp-10-9251-2010, 2010.

Lance, S.: Coincidence errors in a cloud droplet probe (CDP) and a cloud and aerosol spectrometer (CAS), and the improved performance of a modified CDP, J. Atmos. Ocean. Tech., 29, 15321541, https://doi.org/10.1175/JTECH-D-11-00208.1, 2012.

Lance, S., Brock, C. A., Rogers, D., and Gordon, J. A.: Water droplet calibration of the cloud droplet probe (CDP) and in-flight performance in liquid, ice and mixed-phase clouds during ARCPAC, Atmos. Meas. Tech., 3, 1683-1706, https://doi.org/10.5194/amt-3-1683-2010, 2010.

Machado, L. A. T., Silva Dias, M. A. F., Morales, C., Fisch, G., Vila, D., Albrecht, R., Goodman, S. J., Calheiros, A. J. P., Biscaro, T., Kummerow, C., Cohen, J., Fitzjarrald, D., Nascimento, E. L., Sakamoto, M. S., Cunningham, C., Chaboureau, J. P., Pe- tersen, W. A., Adams, D. K., Baldini, L., Angelis, C. F., Sapucci, L. F., Salio, P., Barbosa, H. M. J., Landulfo, E., Souza, R. A. F., Blakeslee, R. J., Bailey, J., Freitas, S., Lima, W. F. A., and Tokay, A.: The CHUVA project: how does convection vary across Brazil?, B. Am. Meteorol. Soc., 95, 1365-1380, https://doi.org/10.1175/BAMS-D-13-00084.1, 2014.

Mallaun, C., Giez, A., and Baumann, R.: Calibration of 3-D wind measurements on a single-engine research aircraft, Atmos. Meas. Tech., 8, 3177-3196, https://doi.org/10.5194/amt-8-3177-2015, 2015.

Martin, S. T., Artaxo, P., Machado, L. A. T., Manzi, A. O., Souza, R. A. F., Schumacher, C., Wang, J., Andreae, M. O., Barbosa, H. M. J., Fan, J., Fisch, G., Goldstein, A. H., Guenther, A., Jimenez, J. L., Pöschl, U., Silva Dias, M. A., Smith, J. N., and Wendisch, M.: Introduction: Observations and modeling of the Green Ocean Amazon (GoAmazon2014/5), Atmos. Chem. Phys., 16, 47854797, https://doi.org/10.5194/acp-16-4785-2016, 2016.

Mikhailov, E., Vlasenko, S., Rose, D., and Pöschl, U.: Mass-based hygroscopicity parameter interaction model and measurement of atmospheric aerosol water uptake, Atmos. Chem. Phys., 13, 717740, https://doi.org/10.5194/acp-13-717-2013, 2013.

Molleker, S., Borrmann, S., Schlager, H., Luo, B., Frey, W., Klingebiel, M., Weigel, R., Ebert, M., Mitev, V., Matthey, R., Woiwode, W., Oelhaf, H., Dörnbrack, A., Stratmann, G., Groo $\beta$, J. U., Günther, G., Vogel, B., Müller, R., Krämer, M., Meyer, J., and Cairo, F.: Microphysical properties of synoptic-scale polar stratospheric clouds: in situ measurements of unexpectedly large $\mathrm{HNO}_{3}$-containing particles in the arctic vortex, Atmos. Chem. Phys., 14, 10785-10801, https://doi.org/10.5194/acp-14-107852014, 2014.

Moore, R. H., Thornhill, K. L., Weinzierl, B., Sauer, D.1, D’Ascoli, E., Kim, J., Lichtenstern, M., Scheibe, M., Beaton, B., Beyersdorf, A. J., Barrick, J., Bulzan, D., Corr, C. A., Crosbie, E., Jurkat, T., Martin, R., Riddick, D., Shook, M., Slover, G., Voigt, C., White, R., Winstead, E., Yasky, R., Ziemba, L. D., Brown, A., Schlager, H., and Anderson, B. E.: Biofuel blending reduces particle emissions from aircraft engines at cruise conditions, Nature, 543, 411-415, https://doi.org/10.1038/nature21420, 2017.

Petters, M. D. and Kreidenweis, S. M.: A single parameter representation of hygroscopic growth and cloud condensation nucleus activity, Atmos. Chem. Phys., 7, 1961-1971, https://doi.org/10.5194/acp-7-1961-2007, 2007.

Pinsky, M., Khain, A., Mazin, I., and Korolev, A.: Analytical estimation of droplet concentration at cloud base, J. Geophys. Res.-Atmos., 117, 1-14, https://doi.org/10.1029/2012JD017753, 2012.

Pöhlker, M. L., Pöhlker, C., Ditas, F., Klimach, T., Hrabe de Angelis, I., Araújo, A., Brito, J., Carbone, S., Cheng, Y., Chi, X., Ditz, R., Gunthe, S. S., Kesselmeier, J., Kónemann, T., Lavric, J. V., Martin, S. T., Mikhailov, E., Moran-Zuloaga, D., Rose, D., Saturno, J., Su, H., Thalman, R., Walter, D., Wang, J., Wolff, S., Barbosa, H. M. J., Artaxo, P., Andreae, M. O., and Pöschl, U.: Longterm observations of cloud condensation nuclei in the Amazon rain forest - Part 1: Aerosol size distribution, hygroscopicity, and new model parametrizations for CCN prediction, Atmos. Chem. Phys., 16, 15709-15740, https://doi.org/10.5194/acp-16-157092016, 2016. 
Pruppacher, H. R., Klett, J. D., and Wang, P. K.: Microphysics of clouds and precipitation, Aerosol Sci. Tech., 28, 381-382, https://doi.org/10.1080/02786829808965531, 1998.

Reutter, P., Su, H., Trentmann, J., Simmel, M., Rose, D., Gunthe, S. S., Wernli, H., Andreae, M. O., and Pöschl, U.: Aerosol- and updraft-limited regimes of cloud droplet formation: influence of particle number, size and hygroscopicity on the activation of cloud condensation nuclei (CCN), Atmos. Chem. Phys., 9, 70677080, https://doi.org/10.5194/acp-9-7067-2009, 2009.

Roberts, G. C. and Nenes, A.: A continuous-flow streamwise thermal-gradient $\mathrm{CCN}$ chamber for atmospheric measurements, Aerosol Sci. Tech., 39, 206-221, https://doi.org/10.1080/027868290913988, 2005.

Rose, D., Gunthe, S. S., Mikhailov, E., Frank, G. P., Dusek, U., Andreae, M. O., and Pöschl, U.: Calibration and measurement uncertainties of a continuous-flow cloud condensation nuclei counter (DMT-CCNC): CCN activation of ammonium sulfate and sodium chloride aerosol particles in theory and experiment, Atmos. Chem. Phys., 8, 1153-1179, https://doi.org/10.5194/acp8-1153-2008, 2008.

Rosenberg, P. D., Dean, A. R., Williams, P. I., Dorsey, J. R., Minikin, A., Pickering, M. A., and Petzold, A.: Particle sizing calibration with refractive index correction for light scattering optical particle counters and impacts upon PCASP and CDP data collected during the Fennec campaign, Atmos. Meas. Tech., 5, 1147-1163, https://doi.org/10.5194/amt-5-1147-2012, 2012.

Rosenfeld, D. and Gutman, G.: Retrieving microphysical properties near the tops of potential rain clouds by multispectral analysis of AVHRR data, Atmos. Res., 34, 259-283, https://doi.org/10.1016/0169-8095(94)90096-5, 1994.

Rosenfeld, D., Woodley, W. L., Krauss, T. W., and Makitov, V.: Aircraft microphysical documentation from cloud base to anvils of hailstorm feeder clouds in Argentina, J. Appl. Meteorol. Clim., 45, 1261-1281, https://doi.org/10.1175/JAM2403.1, 2006.

Rosenfeld, D., Lohmann, U., and Raga, G.: Flood or drought: how do aerosols affect precipitation?, Science, 321, 1309-1313, 2008.

Rosenfeld, D., Fischman, B., Zheng, Y., Goren, T., and Giguzin, D.: Combined satellite and radar retrievals of drop concentration and CCN at convective cloud base, Geophys. Res. Lett., 41, 32593265, https://doi.org/10.1002/2014GL059453, 2014a.

Rosenfeld, D., Chemke, R., Prather, K., Suski, K., Comstock, J. M., Schmid, B., Tomlinson, J., and Jonsson, H.: Polluting of winter convective clouds upon transition from ocean inland over central California: contrasting case studies, Atmos. Res., 135-136, 112127, https://doi.org/10.1016/j.atmosres.2013.09.006, 2014b.

Rosenfeld, D., Zheng, Y., Hashimshoni, E., Pöhlker, M. L., Jefferson, A., Pöhlker, C., Yu, X., Zhu, Y., Liu, G., Yue, Z., Fischman, B., Li, Z., Giguzin, D., Goren, T., Artaxoi, P., Barbosai, H. M. J., Pöschl, U., and Andreae, M. O.: Satellite retrieval of cloud condensation nuclei concentrations by using clouds as CCN chambers, P. Natl. Acad. Sci. USA, https://doi.org/10.1073/pnas.1514044113, in press, 2016.

Schumann, U., Mayer, B., Gierens, K., Unterstrasser, S., Jessberger, P., Petzold, A., Voigt, C., and Gayet, J.-F.: Effective radius of ice particles in cirrus and contrails, J. Atmos. Sci., 68, 300-321, https://doi.org/10.1175/2010JAS3562.1, 2011.

Silva Dias, M. A. F., Petersen, W., Silva Dias, P. L., Cifelli, R., Betts, A. K., Longo, M., Gomes, A. M., Fisch, G. F., Lima, M. A., Antonio, M. A., and Albrecht, R. I.: A case study of convective orga- nization into precipitating lines in the southwest Amazon during the WETAMC and TRMM-LBA, J. Geophys. Res.-Atmos., 107, 8078, https://doi.org/10.1029/2001JD000375, 2002.

Stephens, G.: The parameterization of radiation for numerical weather prediction and climate models, Mon. Weather Rev., 112, 826-867, 1984.

Strapp, J. W., Oldenburg, J., Ide, R., Lilie, L., Bacic, S., Vukovic, Z., Oleskiw, M., Miller, D., Emery, E., and Leone, G.: Wind tunnel measurements of the response of hot-wire liquid water content instruments to large droplets, J. Atmos. Ocean. Tech., 20, 791-806, https://doi.org/10.1175/15200426(2003)020<0791:WTMOTR>2.0.CO;2, 2003.

Ten Hoeve, J. E., Remer, L. A., and Jacobson, M. Z.: Microphysical and radiative effects of aerosols on warm clouds during the Amazon biomass burning season as observed by MODIS: Impacts of water vapor and land cover, Atmos. Chem. Phys., 11, 3021-3036, https://doi.org/10.5194/acp-11-3021-2011, 2011.

Twomey, S.: The nuclei of natural cloud formation part II: the supersaturation in natural clouds and the variation of cloud droplet concentration, Geofis. Pura Appl., 43, 243-249, https://doi.org/10.1007/BF01993560, 1959.

Voigt, C., Schumann, U., Jurkat, T., Schäuble, D., Schlager, H., Petzold, A., Gayet, J. F., Krämer, M., Schneider, J., Borrmann, S., Schmale, J., Jessberger, P., Hamburger, T., Lichtenstern, M., Scheibe, M., Gourbeyre, C., Meyer, J., Kübbeler, M., Frey, W., Kalesse, H., Butler, T., Lawrence, M. G., Holzäpfel, F., Arnold, F., Wendisch, M., Döpelheuer, A., Gottschaldt, K., Baumann, R., Zöger, M., Sölch, I., Rautenhaus, M., and Dörnbrack, A.: In-situ observations of young contrails - overview and selected results from the CONCERT campaign, Atmos. Chem. Phys., 10, 90399056, https://doi.org/10.5194/acp-10-9039-2010, 2010.

Voigt, C., Schumann, U., Jessberger, P., Jurkat, T., Petzold, A., Gayet, J. F., Krmer, M., Thornberry, T., and Fahey, D. W.: Extinction and optical depth of contrails, Geophys. Res. Lett., 38, L11806, https://doi.org/10.1029/2011GL047189, 2011.

Voigt, C., Schumann, U., Minikin, A., Abdelmonem, A., Afchine, A., Borrmann, S., Boettcher, M., Buchholz, B., Bugliaro, L., Costa, A., Curtius, J., Dollner, M., Dörnbrack, A., Dreiling, V., Ebert, V., Ehrlich, A., Fix, A., Forster, L., Frank, F., Fütterer, D., Giez, A., Graf, K., Grooß, J., Groß, S., Heimerl, K., Heinold, B., Hüneke, T., Järvinen, E., Jurkat, T., Kaufmann, S., Kenntner, M., Klingebiel, M., Klimach, T., Kohl, R., Krämer, M., Krisna, T., Luebke, A., Mayer, B., Mertes, S., Molleker, S., Petzold, A., Pfeilsticker, K., Port, M., Rapp, M., Reutter, P., Rolf, C., Rose, D., Sauer, D., Schäfler, A., Schlage, R., Schnaiter, M., Schneider, J., Spelten, N., Spichtinger, P., Stock, P., Walser, A., Weigel, R., Weinzierl, B., Wendisch, M., Werner, F., Wernli, H., Wirth, M., Zahn, A., Ziereis, H., and Zöger, M.: ML-CIRRUS - the airborne experiment on natural cirrus and contrail cirrus with the high-altitude long-range research aircraft HALO, B. Am. Meteorol. Soc., 98, 271-288, https://doi.org/10.1175/BAMS-D-1500213.1, 2017.

Weigel, R., Spichtinger, P., Mahnke, C., Klingebiel, M., Afchine, A., Petzold, A., Krämer, M., Costa, A., Molleker, S., Jurkat, T., Minikin, A., and Borrmann, S.: Thermodynamic correction of particle concentrations measured by underwing probes on fast flying aircraft, Atmos. Meas. Tech., 9, 5135-5162, https://doi.org/10.5194/amt-9-5135-2016, 2016. 
Wendisch, M. and Brenguier, J.-L. (Eds.): Airborne measurements for environmental research: methods and instruments, WileyVCH Verlag GmbH \& Co. KGaA, Weinheim, Germany, 655 pp., https://doi.org/10.1002/9783527653218, 2013.

Wendisch, M., Keil, A., and Korolev, A. V.: FSSP characterization with monodisperse water droplets, J. Atmos. Ocean. Tech., 13, 1152-1165, https://doi.org/10.1175/15200426(1996)013<1152:FCWMWD>2.0.CO;2, 1996.

Wendisch, M., Pöschl, U., Andreae, M. O., Machado, L. A. T., Albrecht, R., Schlager, H., Rosenfeld, D., Martin, S. T., Abdelmonem, A., Afchine, A., Araùjo, A., Artaxo, P., Aufmhoff, H., Barbosa, H. M. J., Borrmann, S., Braga, R., Buchholz, B., Cecchini, M. A., Costa, A., Curtius, J., Dollner, M., Dorf, M., Dreiling, V., Ebert, V., Ehrlich, A., Ewald, F., Fisch, G., Fix, A., Frank, F., Fütterer, D., Heckl, C., Heidelberg, F., Hüneke, T., Jäkel, E., Järvinen, E., Jurkat, T., Kanter, S., Kästner, U., Kenntner, M., Kesselmeier, J., Klimach, T., Knecht, M., Kohl, R., Kölling, T., Krämer, M., Krüger, M., Krisna, T. C., Lavric, J. V., Longo, K., Mahnke, C., Manzi, A. O., Mayer, B., Mertes, S., Minikin, A., Molleker, S., Münch, S., Nillius, B., Pfeilsticker, K., Pöhlker, C., Roiger, A., Rose, D., Rosenow, D., Sauer, D., Schnaiter, M., Schneider, J., Schulz, C., de Souza, R. A. F., Spanu, A., Stock, P., Vila, D., Voigt, C., Walser, A., Walter, D., Weigel, R., Weinzierl, B., Werner, F., Yamasoe, M. A., Ziereis, H., Zinner, T., and Zöger, M.: The ACRIDICON-CHUVA campaign: studying tropical deep convective clouds and precipitation over Amazonia using the new german research aircraft HALO, B. Am. Meteorol. Soc., 97, 1885-1908, https://doi.org/10.1175/BAMS-D-14$00255.1,2016$.
Zheng, Y., Rosenfeld, D., and Li, Z.: Satellite Inference of Thermals and Cloud-Base Updraft Speeds Based on Retrieved Surface and Cloud-Base Temperatures, J. Atmos. Sci., 72, 24112428, https://doi.org/10.1175/JAS-D-14-0283.1, 2015. 